Florida International University FIU Digital Commons

$11-10-2016$

\title{
EEG Spectral Changes Before and After an Eight- week Intervention Period of Preksha Meditation
}

Chintan Joshi

cjosh002@fiu.edu

DOI: $10.25148 /$ etd.FIDC001244

Follow this and additional works at: https://digitalcommons.fiu.edu/etd

Part of the Biomedical Engineering and Bioengineering Commons

\section{Recommended Citation}

Joshi, Chintan, "EEG Spectral Changes Before and After an Eight-week Intervention Period of Preksha Meditation" (2016). FIU Electronic Theses and Dissertations. 2981.

https://digitalcommons.fiu.edu/etd/2981 


\section{Florida International University \\ FIU Digital Commons}

FIU Electronic fteses and Dissertations University Graduate School

$11-10-2016$

\section{EEG Spectral Changes Before and After an Eight-week Inter vention Period of Preksha Meditation}

Chintan Joshi

Follow this and additional works at: http://digitalcommons.fiu.edu/etd 


\title{
FLORIDA INTERNATIONAL UNIVERSITY
}

Miami, Florida

\section{EEG SPECTRAL CHANGES BEFORE AND AFTER AN EIGHT-WEEK INTERVENTION PERIOD OF PREKSHA MEDITATION}

\author{
A thesis submitted in partial fulfillment of the \\ requirements for the degree of \\ MASTER OF SCIENCE \\ in \\ BIOMEDICAL \\ ENGINEERING \\ by \\ Chintan Joshi
}


To: Interim Dean Ranu Jung

College of Engineering and Computing

This thesis, written by Chintan Joshi, titled EEG Spectral Changes Before and After an Eight-week Intervention Period of Preksha Meditation having been approved in respect to style and intellectual content, is referred to you for judgment.

We have read this dissertation and recommend that it be approved.

$\begin{array}{r}\hline \text { Wei-Chiang Lin } \\ \hline \text { Jorge Riera } \\ \hline \text { Major Professor, Ranu Jung }\end{array}$

Date of Defense: November 10, 2016

The thesis of Chintan Joshi is approved.

Interim Dean Ranu Jung College of Engineering and Computing

Andrés. G. Gil

Vice President for Research and Economic Development and Dean of the University Graduate School

Florida International University, 2016 


\section{DEDICATION}

Dedicated to my family - without their love, support and sacrifice this thesis would not have been completed. 


\section{ACKNOWLEDGMENTS}

I sincerely thank my mentor, Dr. Ranu Jung, for her extensive support throughout the span of my Master's - without her continued guidance and support this work would not

have been possible. Dr. Jung helped me in developing the ability to think both critically and creatively. She has provided me with every opportunity to grow. I am grateful for all the kindness and patience that she has shown me over the years.

I wish to thank Dr. Jorge Riera for his support and critical guidance for this work. He has always provided me his time from busy schedule to discuss any difficulties I faced.

I would specially like to thank Anil Kumar Thota, for his continued support and guidance for this work. I would say that I learned a lot about Signal Processing and Matlab scripting from him. He is the best mentor. Thanks Anil, for developing a friendly environment and making me understand the core fundamentals needed for this project, which I had very scarce knowledge.

I would like to thank all my lab members, Dr. Liliana Rincon Gonzales, Dr. Brian Hillen, Srinidhi (SK), Andres Pena, Ricardo Siu, Ashfaq Ahmed (Polit), Iian Black, Jefferson Gomes. They have always helped me out whenever I needed help with any research or personal help. They also have provided great feedback on my work during the lab meetings.

I would like to thank Samani Unnata Pragya (Samaniji) for her continuous motivation and helping me find subjects for data collection. A special word of thanks goes to Claudia Estrada and Andrew Green, who have been very helpful and caring and have supported me for all administrative needs. 
I would like to thank all my family members, especially my parents, sisters, brother inlaw's, cousins, uncle, and aunt. You are my biggest strength in life, without your unconditional love and support this day would not have come.

Lastly, I would like to thank all of you whose name I forgot to write, but learned important lessons from you. 


\title{
ABSTRACT OF THE THESIS \\ EEG SPECTRAL CHANGES BEFORE AND AFTER AN EIGHT WEEK \\ INTERVENTION PERIOD OF PREKSHA MEDITATION
}

\author{
by \\ Chintan Joshi \\ Florida International University 2016 \\ Miami, Florida \\ Professor Ranu Jung, Major Professor
}

Various types of meditation techniques, primarily categorized into concentrative and mindfulness meditation, have evolved over the years to enhance the physiological and psychological well-being of people in all walks of life. However, the scientific knowledge of the impact of meditation on physiological and psychological well-being is very limited. Electroencephalography (EEG) was used to study the effect of a sequence of different forms of Preksha meditation on brain activity. EEG data from 13 novice participants ( 10 females, 3 males; Age: 19-49 yrs) were collected while meditating for the first time and at the end of an eight-week intervention period (3 meditation sessions/week). EEG spectral power densities were calculated in delta $(1-4 \mathrm{~Hz})$, theta $(4-8 \mathrm{~Hz})$, alpha $(8-13 \mathrm{~Hz})$, beta $(13-40 \mathrm{~Hz})$ and gamma (40-100Hz) bands. A Support vector machine algorithm was used to classify different forms of Preksha meditation. The SVM classification was able to differentiate the brain activity amongst the forms of Preksha meditation with 6-12\% accuracy only. These accuracies are extremely low and the classification was not able to discriminate between different forms of meditation within a session. It is therefore concluded, that the format of Preksha meditation utilized did not elicit clear changes in EEG, discernable using the SVM algorithm. 
Chapter $1 \quad$ INTRODUCTION

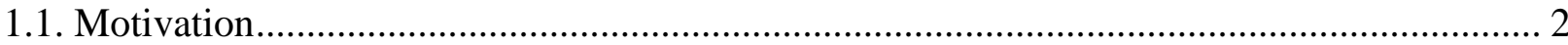

1.2. Objective

1.3. Specific Aims and Hypotheses ....................................................................................... 3

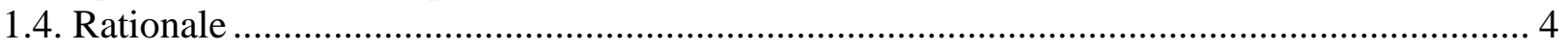

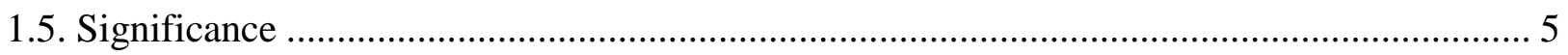

1.6. Organization of the Thesis ......................................................................................... 5

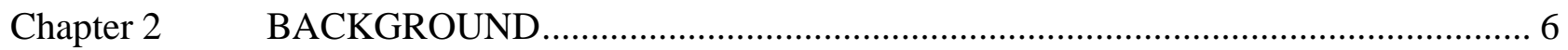

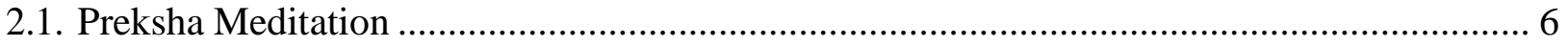

2.2. Components (Forms) of Preksha Meditation .................................................................... 6

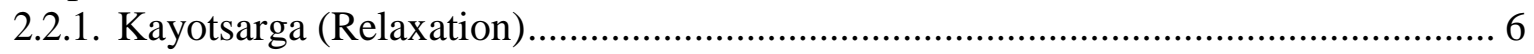

2.2.2. Antaryatra (Internal trip) .................................................................................. 7

2.2.3. Shvasa Preksha (Perception of breathing) .............................................................. 7

2.2.4. Sharir Preksha (Perception of physical body) ………........................................... 7

2.2.5. Leshya Dhyan (Perception of psychic color) ........................................................... 7

2.2.6. Anupreksha (contemplation) ........................................................................... 7

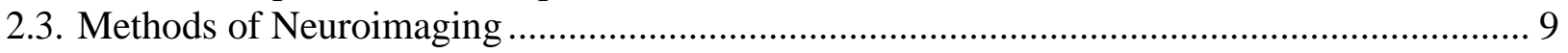

2.3.1. Electroencephalography ................................................................................ 9

2.3.1.1. Brain Waves: .............................................................................................. 10

2.3.2. Functional Magnetic Resonance Imaging (f-MRI) .............................................. 12

2.3.3. Positron Emission Tomography (PET) ……………............................................. 12

2.3.4. Single Photon Emission Computed Tomography (SPECT)...................................... 13

2.3.5. Magnetoencephalography (MEG) ...................................................................... 13

2.3.6. Near Infrared Spectroscopy (NIRS) ………………......................................... 14

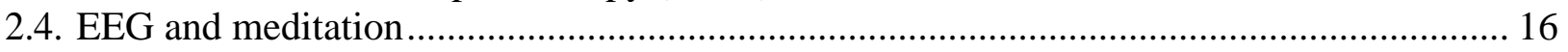

2.4.1. Impact of Concentrative meditation on EEG activity ............................................ 16

2.4.2. Impact of Mindfulness meditation on EEG activity.............................................. 17

2.4.3. Impact of concentrative and mindfulness meditation (combined) on EEG ............. 17

2.4.4. Impact of visual color perception on brain activity ............................................... 18

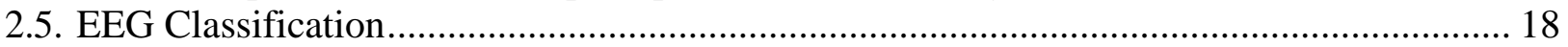

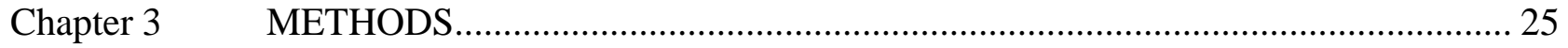

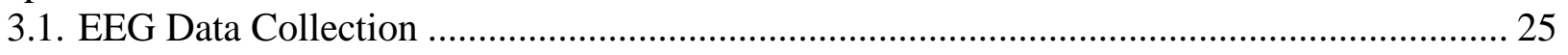

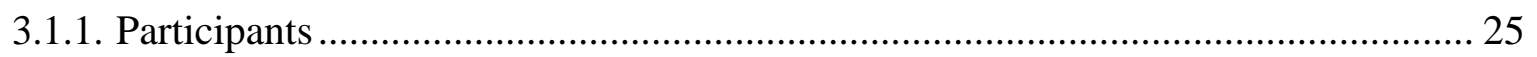

3.1.2. Participants Preparation: ............................................................................... 25

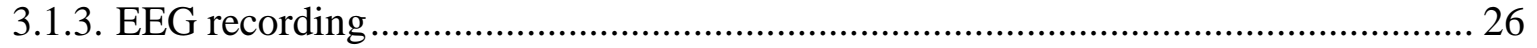

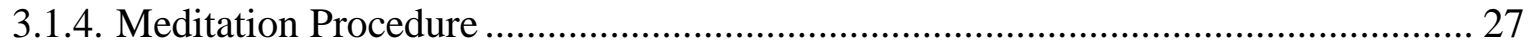

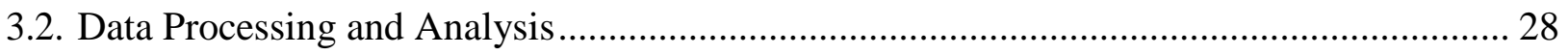

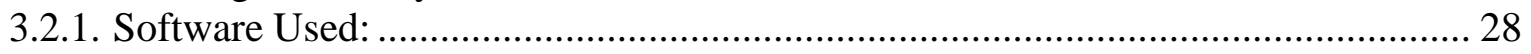

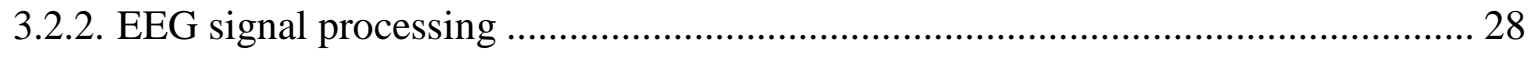




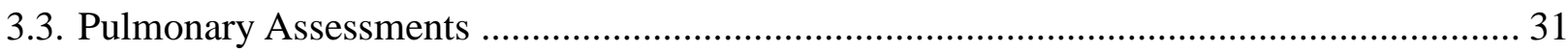

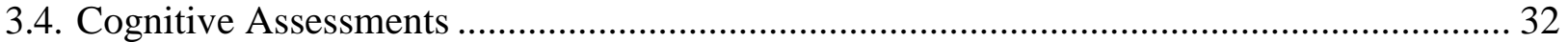

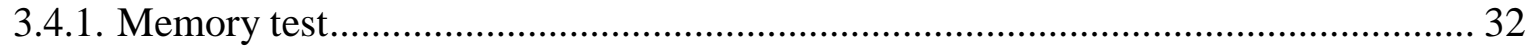

3.4.2. Positive Affect and Negative Affect Schedule (PANAS) test: ........................... 33

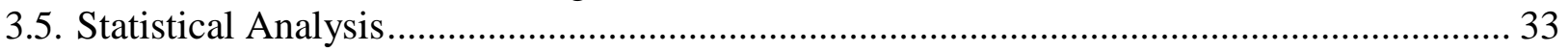

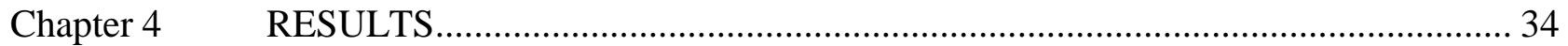

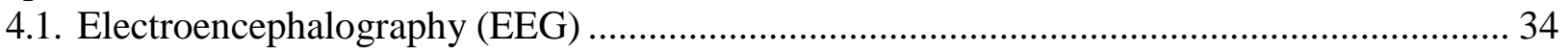

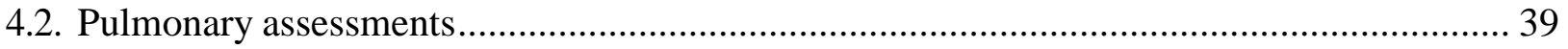

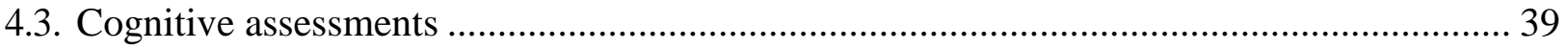

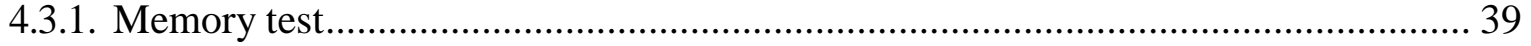

4.3.2. Positive and Negative Affect Schedule (PANAS) test: ................................... 40

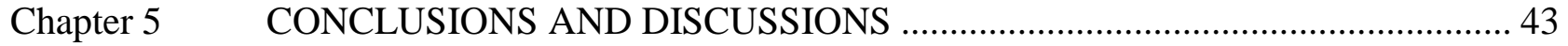

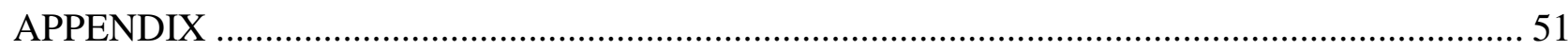




\section{LIST OF FIGURES}

FIGURE

PAGE

Figure 1: A working diagram of Linear Support Vector Machine (SVM) classifier ................... 20

Figure 2: A working diagram of K-nearest neighbor $(\mathrm{KNN})$ classifier................................... 21

Figure 3: A 2D montage of EEG cap displaying all the electrodes .........................................26

Figure 4: EEG routines implemented throughout the study .............................................. 26

Figure 5: Different combinations of channels and bands................................................. 29

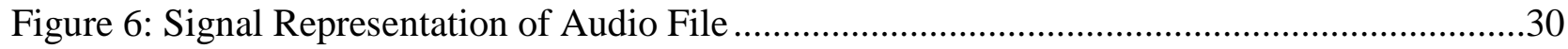

Figure 7: Description of how data, all was processed in Machine Learning...............................30

Figure 8: Complete Block diagram of data processing (a) Placement of EEG cap on the

subject's scalp (b) The view of raw EEG of the subject recorded during meditation...

Figure 9: Overall classification accuracy for all the predictors (A) Classification accuracy in the pre session (B) Classification accuracy in the post session ............................................35

Figure 10: Sensitivity of different predictors for Buzzing-brain meditation in the pre session......36

Figure 11: Sensitivity of different predictors for Buzzing-breathe meditation in the pre session...36

Figure 12: Sensitivity of different predictors for green color meditation in the pre session........37

Figure 13: Sensitivity of different predictors for Buzzing-brain meditation in the post Session .. 37

Figure 14: Sensitivity of different predictors for Buzzing-breathe meditation in the post session 38

Figure 15: Sensitivity of different predictors for green meditation in the post session..................38

Figure 16: Raw scores of all the subjects performing memory task .......................................40

Figure 17: Mean and standard deviation of the raw scores for all the subjects in memory task Digit Recall, Listening Recall, Listening Recall Processing, Spatial Recall, Spatial Recall Processing.....

Figure 18: Error bars for each of the 10 positive moods for all the subjects. Blue error bar indicates pre study (before eight-weeks intervention period) and red error bar indicates post study (after eight-week intervention period)

Figure 19: Error bars for each of the 10 negative moods for all the subjects. Blue error bar indicates pre study (before eight-weeks intervention period) and red error bar indicates post study (after eight-week intervention period) 


\section{ABBREVIATIONS AND ACRONYMS}

ASA - Advanced Source Analysis Software.

AWMA - Automated Working Memory

Assessment EEG - Electroencephalography

EEGLAB - Electroencephalography

Laboratory FEV - Forced Expiratory Volume

FVC - Forced Vital capacity

F-MRI - Functional Magnetic Resonance

Imaging MEG - Magnetoencephalography

NIRS - Near Infrared Spectroscopy

PANAS - Positive Affect and Negative Affect

Schedule PEF - Peak Expiratory Flow

PET - Positron Emission

Tomography PFT - Pulmonary

Function Test

SPECT - Single photon Emission Computed

Tomography TM - Transcendental Meditation

TPR - True Positive Ratio 


\section{Chapter 1 INTRODUCTION}

Meditation is known as a technique to train one's mind to achieve a state of consciousness that is totally different from the normal awake state. It is also considered as a means to transform the mind and achieve a state where the mind is free of thoughts. Meditation also refers to diverse practices, ranging from health exercises to exercises that are performed for achieving a heightened sense of well-being (R. Davidson \& Lutz, 2008). Meditation is also used as a mind-body practice in complementary and alternative medicine. Meditation is largely an internal, personal practice and is commonly exercised without any external involvement. It can be performed by meditators while sitting, with their spine kept upright and the rest of the body neither too relaxed nor too tense. Most often it is practiced daily from several minutes to hours. Such regular practice of meditation has been shown to improve cognitive components like enhanced sustained attention (MacLean et al., 2010) and increased attentional stability (Lutz et al., 2009). Some people use meditation as a method for reducing stress and anxiety or against symptoms of depression (Pilkington et.al., 2005). A recent study by (Perich et al., 2013) showed that meditation, can in general, increase relaxation, emotional well-being, cognitive function and can act as a tool to synchronize the mind and body (Kok, Waugh, \& Fredrickson, 2013).

There are several forms of meditation from different religious practices like Buddhism, Hinduism and Christianity, which vary in the style, tradition and purpose. These varied styles and forms of meditation have evolved over years and are said to enhance the physiological and psychological well-being of people in all walks of life. In general, all these forms of meditation fall under two major categories: Concentrative meditation or Mindfulness meditation. 
Concentrative meditation is the most widely practiced form of meditation (Lutz, et.al, 2006). This meditation requires the practitioner to focus on a specific object like breath, image, part of the body etc. The simplest method for developing concentration is to focus on the flow of breath. This type of meditation is considered as a way to quite the busy mind and thus help improve concentration. Different meditation types like Kundalini yoga, a practice which includes concentrating on the breath flowing through the energy centers of the body and mantra meditation, which includes chanting of sacred word or syllable like 'OM' with eyes closed, fall under this category.

Mindfulness meditation, on the other hand, is allowing your thoughts, feelings and sensations to arise while staying aware of yourself and your location (Cahn \& Polich, 2006).This type of meditation is not only difficult to practice but also requires several years of practice (Fell, Axmacher, \& Haupt, 2010). Mindfulness meditation develops an individual's mind to be non-reactive even during unpleasant and painful situations. Vipassana meditation, a Buddhist practice that involves focusing on the present-moment, sensory awareness with an equanimous and non-reactive mental set (Gunaratana, 2002) and compassion meditation, also a Buddhist form of practice which involves developing and evoking a feeling of compassion towards others, fall under this category. Some meditation forms, for instance, Qi-gong, Preksha meditation (PM), Transcendental meditation (TM) and Zen meditation involve a combination of both these approaches.

\subsection{Motivation}

Different forms of meditation, as described above, have been practiced extensively by many people, and are considered as an effective tool for coping with stress and stress inducing thoughts. It has been claimed that regular meditation practice helps rewire your brain thereby 
helping improve focus, memory and other cognitive functions. A study performed by Lazar et.al. (Lazar et al., 2005) found that brain regions associated with attention and sensory processing were thicker in meditators compared to controls. Newberg \& Iversen reported that Buddhist meditative practice can alter the brain activity in areas important for sensory, cognitive and emotional processing and thus enable the practitioners to absorb and process more information. (Newberg \& Iversen, 2003) A couple of weeks of mindfulness meditation training has helped people gain focus and memory during the verbal reasoning section of GRE (Mrazek, Franklin, Phillips, Baird, \& Schooler, 2013). Such are the benefits of meditation, yet, very little is known about meditation and its impact on the brain (Lutz, Greischar, Rawlings, Ricard, \& Davidson, 2004). Also, a full-fledged theory till date, about the effects of meditation does not exist (Sedlmeier et al., 2012). A proper understanding of the brain mechanism(s) underlying meditation could help enhance our knowledge of the various cognitive benefits related to different meditation techniques and would also answer the question, how does the brain respond to meditation?

\subsection{Objective}

The overall objective of the presented research was to understand changes in neural activity during Preksha meditation, a combination of Concentrative as well as Mindfulness form of meditation, using a quantitative technique, Electroencephalography. The overall goal is divided into two specific aims as follows:

\subsection{Specific Aims and Hypotheses}

Aim 1: To investigate the effect of buzzing (concentrative) meditation on the brain activity. 
Hypothesis 1: The EEG of meditators performing buzzing meditation will show an increase in theta $(4-8 \mathrm{~Hz})$ and gamma $(40-100 \mathrm{~Hz})$ band activity after an eight-week intervention period of Preksha meditation.

Aim 2: To investigate the effect of green color (mindfulness) meditation on the brain activity. Hypothesis 2: The EEG of meditators performing green color meditation will show an increase in alpha $(8-13 \mathrm{~Hz})$ activity after an eight-week intervention period of Preksha meditation.

Aim 3: To understand the pulmonary and cognitive function associated with Preksha meditation.

\section{Hypothesis 3:}

For PFT: The inspiration and expiration lung capacity should increase after an eight-week intervention compared to before intervention.

For cognitive (memory) test: There should be an increase in the memory performance of subjects after an eight-weeks intervention compared to before.

\subsection{Rationale}

Rationale 1: Various neuroimaging studies have shown changes in the anterior cingulate cortex (ACC) when a person is required to sustain attention or process representations in working memory (Matochik, Zametkin, Cohen, Hauser, \& Weintraub, 1996). This ACC is the main source of generation of theta rhythms (Gevins, Smith, McEvoy, \& Yu, 1997). Also, the theta rhythm is considered as a monitor for focused attention and concentrative meditation (Baijal \& Srinivasan, 2010) whereas the gamma rhythm helps in binding populations of neurons required for performing motor activity (Tallon-Baudry, Kreiter, \& 
Bertrand, 1999).

Rationale 2: Green color is the shorter wavelength color which is experienced as calming (Stone \& English, 1998) and the alpha rhythm is the rhythm associated with relaxed or calm state (Stinson \& Arthur, 2013).

\subsection{Significance}

The study has examined the changes in EEG associated with different forms of Preksha meditation in novice meditators. This information could be used in the future to provide

evidence - based support as to which changes in EEG are associated with different forms of Preksha meditation and it can be used as a means to achieve spiritual well-being. Since, meditation, in general is known to have various psychological benefits, it would be of great importance to show the underlying neural mechanisms involved in meditation.

\subsection{Organization of the Thesis}

This thesis is organized into different chapters as follows:

Chapter1 provides an introduction to the thesis, and presents the motivation behind this research, hypotheses, specific aims, rationale and significance of the study. Chapter 2 provides a comprehensive review of the literature in the field of meditation and EEG, background information on meditation practice, including Preksha meditation, methods of neuroimaging and classification algorithms. Chapter 3 presents the research methods, experimental protocols utilized to conduct the study of EEG and various physiological measures, pulmonary and cognitive tests to understand physiological changes during Preksha meditation. In chapter 4, the study results are presented and chapter 5 presents a discussion of the results, the conclusions and potential future research work. The thesis ends with a list of 
references. Appendix 1 provides a detailed description of the audio file played in both pre and post sessions. 


\section{Chapter 2 BACKGROUND}

In this chapter, a brief introduction to Preksha meditation, methods of neuroimaging and a comprehensive literature of neuropsychological factors underlying meditation are addressed. We have also addressed the selection of one neuroimaging technique over another.

\subsection{Preksha Meditation}

Preksha meditation, is a meditation practice of Jainism, a religious group of Indian origin, formulated by the tenth spiritual leader, Acharya Mahapragya in the middle of the $20^{\text {th }}$ century. Preksha means 'to see carefully and deeply'. This means to see deeply without having preferences of likes and dislikes (Mahapragya, 2004). The main aim of Preksha meditation is to reduce the negative emotions and improve physical, mental, and emotional health.The different components/forms of Preksha meditation that a beginner practitioner has to go through in order to attain heighted consciousness are described below.

\subsection{Components (Forms) of Preksha Meditation}

\subsubsection{Kayotsarga (Relaxation)}

It is said that a half an hour of relaxation is equivalent to two hours of sleep in terms of rest and recovery of muscles (Mahapragya, 2003). This component of Preksha meditation includes attempting to relax each body part starting from the toes all the way to the forehead with eyes closed. This is an essential pre-conditioning component preceding meditation as it helps in calming the body and relieving stress/tension.

\subsubsection{Antaryatra (Internal trip)}

In this component, the meditator continuously allows the mind to travel from lower end of 
the spinal cord (center of energy) to the top of the head (center of knowledge) while focusing on the breath. During inhalation, the mind travels from top of the head to the lower end of the spinal cord and vice versa for exhalation.

\subsubsection{Shvasa Preksha (Perception of breathing)}

This component of Preksha meditation involves a breathing exercise, with short inhalations and long exhalations producing a 'humming' sound with lips closed. The humming sound produced should come from the mouth and should be constant for as long as possible. This type of a breathing exercise is also called Mahapran Dhvani or buzzing meditation.

\subsubsection{Sharir Preksha (Perception of physical body)}

This component of Preksha meditation involves awareness of body parts like liver, intestines, heart etc. This awareness is centripetal, i.e. from outside to inside. Commencing from the outer layer of consciousness one has to penetrate deeper and deeper (Mahapragya, 1988).

\subsubsection{Leshya Dhyan (Perception of psychic color)}

In this type of meditation, the meditator visualizes different colors on different energy centers of the body like center of bliss, center of knowledge, center of purity, center of intuition etc. These different energy centers are associated with different colors. In this study, meditators visualized the fourth energy center which is also called as Heart chakra since it is located next to the heart. This psychic center symbolizes green color.

\subsubsection{Anupreksha (contemplation)}

Contemplation is also an important technique of Preksha meditation. In this technique the conscious mind is encouraged to concentrate on a thinking process. 
In order to understand the brain electrical activity involved in the above mentioned components of Preksha meditation, various quantitative neuroimaging techniques could be adopted. Detailed information of different neuroimaging techniques and selection of one technique for this study are discussed below.

\subsection{Methods of Neuroimaging}

Neuroimaging techniques can be categorized into two types: those which directly measure the electrical activity of the neurons such as, Electroencephalography (EEG) and Magnetoencephalography (MEG) and those that utilize an indirect surrogate measure of neuronal activity, such as increased blood-flow and metabolic activity during neural activation. The latter include techniques such as Positron Emission Tomography (PET), functional magnetic resonance imaging (F-MRI), and Near-infrared spectroscopy (NIRS).

\subsubsection{Electroencephalography}

Electroencephalography, is a non-invasive brain mapping technique which records the electrical impulses from the scalp generated from the firing of neurons in the brain (Pizzagalli, 2007). These impulses, called electroencephalograms (EEG) are collected from the scalp via small electric conductors called 'electrodes'. The electrodes are usually made up of metal like gold, silver, zinc or tin. The electrodes placed on the scalp to record the activity are designated by numbers and letters. The letter indicates the area of the brain underneath the electrode, for example, $\mathrm{F}$ for Frontal, $\mathrm{P}$ for Parietal, $\mathrm{T}$ for Temporal and $\mathrm{O}$ for Occipital. The numbers denote the position on the montage with odd numbers denoting the left hemisphere and even numbers denoting the right hemisphere. For proper conductance of electrical activity between the electrode and the scalp, a conducting gel is used. The electrical potentials 
recorded are very subtle and measured in microvolts. To magnify these small potentials, so that they can be displayed on a computer screen, an amplifier is used. This EEG amplifier has filters, voltage dividers, input/output jacks and calibration devices (Mishra, U.K., Kalita, J., 2008) and it magnifies the potentials by approximately one million times of the original input signal.

\subsubsection{Brain Waves:}

Rhythmical EEG activity is generated when neurons communicate with each other, and can be recorded in the form of EEG brainwaves. Brainwaves are representatives of an individual's mental state. Depending on the frequency range of the signal, the brainwaves are classified into five bands named Delta, Theta, Alpha, Beta and Gamma. These brain waves are categorized in terms of frequency bands as they vary in frequency from $0.5-100 \mathrm{~Hz}$.

\section{Delta Wave $(0.5 \mathrm{~Hz}-4 \mathrm{~Hz})$ :}

Delta Waves are the brainwaves which lie in the frequency range of $0.5 \mathrm{~Hz}-4 \mathrm{~Hz}$. These brainwaves are highest in amplitude. Delta waves are primarily associated with deep sleep (Sekimoto et al., 2005) and deeper level of meditation (unconscious mind). These waves are found mostly in the frontal region of the brain in adults and the posterior region in children (Clarke, Barry et.al., 2001).

\section{Theta Wave (4Hz-8Hz):}

Theta waves are the brainwaves which lie in the frequency range of $4 \mathrm{~Hz}-8 \mathrm{~Hz}$. Theta waves are considered to be a bridge between the conscious mind (wakefulness) and the unconscious mind (sleep). Theta activity may also be related to waking and rapid eye movement (REM) sleep (Cantero et al., 2003). Theta waves also occur during short-term memory tasks, when the hippocampus is active (Vertes, 2005). 


\section{Alpha Wave (8Hz-13Hz):}

These are the most dominant waves in the EEG lying in the frequency range of $8 \mathrm{~Hz}$ 13Hz. These waves were first discovered by German neurologist Hans Berger. Hence, these waves are also called 'Berger's waves' (Collura, TF; 1993). Alpha waves are associated with a relaxed mental state with eyes closed (Grandjean, E.; 1988). These waves appear mostly in the posterior regions of the brain when sensory inputs are shut-off (Okogbaa, Shell, \& Filipusic, 1994) (i.e. when eyes are closed, alpha activity is recorded from the posterior regions whereas when eyes are opened, no alpha activity is recorded from the posterior regions).

\section{Beta Waves $(13 \mathrm{~Hz}-40 \mathrm{~Hz})$ :}

These waves lie in the frequency range of $13 \mathrm{~Hz}-40 \mathrm{~Hz}$. Beta waves represent an index of arousal, excitement, active thinking and problem-solving (Grandjean, E.; 1988). When the brain is actively engaged in material activities, beta waves are generated. Normal adults engaged in active conversation, debate, tend to be in the beta state.

\section{Gamma Waves (>40Hz):}

Gamma waves are the fastest waves with the lowest amplitude. The activity around $40 \mathrm{~Hz}$ is termed as gamma activity, but the range can vary substantially between 40 and $200 \mathrm{~Hz}$ across different studies. These waves are involved in high-level processing tasks as well as cognitive functioning. Gamma waves are also important for binding (Lehmann et al., 2001) different neuronal activity during conscious experiences and perception (Singer \& Gray, 1995). Table 1 below shows the complete summary of the brain wave activity during different mental states based on frequency bandwidths (Stinson \& Arthur, 2013). 
Table 1: Summary of brain wave activity

\begin{tabular}{|c|c|c|}
\hline Brain Wave & Frequency (Hz) & Activity \\
\hline Delta & $0.5-4$ & Deep meditation, Sleep \\
\hline Theta & $4-8$ & $\begin{array}{c}\text { Deep relaxation, inward focus, working } \\
\text { memory, enhanced creativity }\end{array}$ \\
\hline Alpha & $8-13$ & Meditation/Relaxation, visualization \\
\hline Beta & $13-40$ & Active conversation, sports, anxiety dominant \\
\hline Gamma & $>40$ & Burst of insights, high level processing \\
\hline
\end{tabular}

\subsubsection{Functional Magnetic Resonance Imaging (f-MRI)}

Functional Magnetic Resonance Imaging (f-MRI), is a non-invasive, rapidly developing technique for assessing human brain function by detecting blood flow differences (Wilke et.al., 2003). f-MRI is used to produce activation maps showing which parts of the brain are involved in mental processes. f-MRI views the tissue differences with respect to time. A baseline state is required in the experimental design, so that the neural activity during a task can be compared to it. The spatial resolution of f-MRI is $6 \mathrm{~mm}$, whereas the temporal resolution is $3 \mathrm{sec}$. The main advantage of f-MRI is accurate depiction of structural data whereas, the main disadvantage of f-MRI is it is noisy and because of that it is rarely applied to research areas like sleep research (Otte et al., 2006) and no metal objects or equipment can be used near the f-MRI machine during a test.

\subsubsection{Positron Emission Tomography (PET)}

PET is a nuclear imaging technique that is used to observe metabolic processes in the body (Muehllehner \& Karp, 2006). PET involves the injection of radioactive material called 
'radiotracer' into the participants. This radiotracer travels through the blood and collects in the neurons that are more active and thus highlights the areas of the brain that are active during a task. The main benefit of a PET scan is that different radiotracers can be used to show blood flow, oxygen and glucose metabolism in the tissues of working brain. The disadvantage of PET is exposure to radiation, cost of operation and the half-lives of the radiotracer is very short. The spatial resolution of PET is $15 \mathrm{~mm}$, while the temporal resolution is $20 \mathrm{~min}$.

\subsubsection{Single Photon Emission Computed Tomography (SPECT)}

SPECT is similar to PET and uses gamma emitting radiotracers and a gamma camera to record the data. It involves injecting a radiotracer to the subjects before the procedure. The uptake of this radiotracer is nearly within 30-60 secs. The main advantage of SPECT is much longer half-lives of the radiotracer. The spatial resolution is $8-12 \mathrm{~mm}$ (Khalil, Tremoleda, Bayomy, \& Gsell, 2011).

\subsubsection{Magnetoencephalography (MEG)}

MEG is a functional neuroimaging technique, that measures the magnetic field produced by the electrical activity in the brain via sensitive electrodes such as superconducting quantum interference devices (SQUIDS). MEG provides a direct measure of brain function. The main advantage of MEG is higher temporal resolution compared to EEG, however recent work suggests otherwise (Malmivuo \& Suihko, 2004) and hence this issue remains controversial. The major disadvantage of MEG is its non-portability and expensive. Also, MEG needs to be paired with MRI. 


\subsubsection{Near Infrared Spectroscopy (NIRS)}

NIRS can measure quantitative changes in concentration of oxygenated and deoxygenated hemoglobin in the blood. The signal measured by NIRS is highly correlated with the BOLD signal measured in fMRI (Cui, Bray, Bryant, Glover, \& Reiss, 2011). The spatial resolution of NIRS, is limited. A detailed comparison of different neuroimaging techniques is described in Table 2 (Markus Ullsperger \& Stefan Debener, 2010). Different neuroimaging modalities will have advantages and disadvantages, and it is not obvious which modality is better than the other for understanding neural mechanisms underlying Preksha meditation. Temporal changes in brain neuronal activity need to be understood in order to conclude the effect of meditation. For this reason, a modality which has high temporal resolution was chosen. In this case, it is EEG. 
Table 2: Detailed comparison of different neuroimaging techniques.

\begin{tabular}{|c|c|c|c|c|c|}
\hline Method & Measure & $\begin{array}{c}\text { Spatial } \\
\text { Resolution }\end{array}$ & $\begin{array}{l}\text { Temporal } \\
\text { Resolution }\end{array}$ & $\begin{array}{l}\text { Invasive } \\
\text { /Non- } \\
\text { invasive }\end{array}$ & Advantages \\
\hline EEG & $\begin{array}{l}\text { Electrical } \\
\text { activity of the } \\
\text { brain }\end{array}$ & $3-5 \mathrm{~cm}$ & $0.02 \mathrm{sec}$ & $\begin{array}{l}\text { Non- } \\
\text { invasive }\end{array}$ & $\begin{array}{l}\text { Portable. } \\
\text { Cost } \\
\text { ineffective. } \\
\text { Good temporal } \\
\text { resolution. }\end{array}$ \\
\hline fMRI & $\begin{array}{l}\text { Changes in the } \\
\text { blood oxygen } \\
\text { level }\end{array}$ & $6 \mathrm{~mm}$ & $3 \operatorname{secs}$ & $\begin{array}{l}\text { Non- } \\
\text { invasive }\end{array}$ & $\begin{array}{l}\text { Excellent } \\
\text { spatial } \\
\text { resolution }\end{array}$ \\
\hline PET & $\begin{array}{l}\text { metabolic } \\
\text { activities of } \\
\text { the brain }\end{array}$ & $15 \mathrm{~mm}$ & $20 \mathrm{~min}$ & Invasive & $\begin{array}{l}\text { Detailed } \\
\text { information of } \\
\text { physiological } \\
\text { parameters }\end{array}$ \\
\hline MEG & $\begin{array}{l}\text { Magnetic } \\
\text { fields } \\
\text { generated by } \\
\text { neuronal } \\
\text { activity of } \\
\text { brain }\end{array}$ & $2-3 \mathrm{~cm}$ & $0.05 \mathrm{sec}$ & $\begin{array}{l}\text { Non- } \\
\text { invasive }\end{array}$ & $\begin{array}{l}\text { Excellent } \\
\text { spatial and } \\
\text { temporal } \\
\text { resolution }\end{array}$ \\
\hline SPECT & Blood flow & $8-12 \mathrm{~mm}$ & & $\begin{array}{l}\text { Non- } \\
\text { invasive }\end{array}$ & $\begin{array}{l}\text { Greater half- } \\
\text { lives of } \\
\text { radiotracers. }\end{array}$ \\
\hline NIRS & $\begin{array}{l}\text { Concentration } \\
\text { of oxy and de- } \\
\text { oxygenated } \\
\text { hemoglobin }\end{array}$ & $1 \mathrm{~cm}$ & $1 \mathrm{sec}$ & $\begin{array}{l}\text { Non- } \\
\text { invasive }\end{array}$ & $\begin{array}{l}\text { Penetrate } \\
\text { deeper into } \\
\text { tissues. }\end{array}$ \\
\hline
\end{tabular}




\subsection{EEG and meditation}

A significant number of studies have been performed to explore the neural dynamics underlying different meditation forms (Kaur \& Singh, 2015)

\subsubsection{Impact of Concentrative meditation on EEG activity}

The relation between EEG activity and concentrative meditation has been investigated extensively (Michael Murphy, Steven Donovan, 1997). The most common findings in the studies of concentrative meditation showed an increase in theta band power (Baijal \& Srinivasan, 2010). Theta band power and coherence was also observed in meditators performing Sahaj Yoga meditation as compared to non-meditators (Aftanas \& Golocheikine, 2002). A study performed on subjects performing concentrative meditation showed increased alpha band activity, which is localized over the frontal regions (Takahashi et al., 2005). Longterm meditation practice resulted in positive changes in behavior and changes in brain activity (Aftanas \& Golocheikine, 2001). These changes included increase in theta activity especially in the frontal areas (Aftanas \& Golocheikine, 2001, 2002). Another study explored the physiological correlates of Kundalini yoga meditators during pre-baseline, meditation, and post-baseline periods (Arambula et.al., 2001). They observed increased alpha band activity during meditation compared to pre-baseline and post-baseline periods. Also, an increase in theta activity immediately following meditation compared to pre-baseline and meditative periods. Increasing attempts have been made to relate theta band activity with the concentrative aspect of Qi-gong meditation (Pan et.al., 1994). An earlier study on Qi-gong meditators showed occipital dominant alpha-2 activity $(8-8.5 \mathrm{~Hz})$. However, a recent followup study conducted on the same subjects with 45 years of experience in Qi-gong meditation 
showed frontally dominant alpha-1 (6.5-8.5 Hz) activity. (Qin, Jin et.al., 2009).

\subsubsection{Impact of Mindfulness meditation on EEG activity}

Mindfulness meditation has been widely accepted as a condition in which alpha brain waves are predominant. It improves creativity, decision making and problem-solving (Stinson \& Arthur, 2013). A recent study using mindfulness meditation reported significant decrease in left-sided anterior alpha power in the meditators compared with the non-meditators (Michael Murphy \& Steven Donovan, 1997). These left sided activations are associated with reduction in anxiety and negative affect and increases in positive affect (R. J. Davidson et al., 2003) This provides a clear indication of mindfulness meditation having a positive effect on practitioners (Sedlmeier et al., 2012). A study on 34 mindfulness meditators showed an overall increase in power in theta and beta band (Ahani et al., 2014). Gamma activity was observed in advanced Tibetan Buddhist practitioners engaged in compassion meditation (Lutz et al., 2004) as a state and trait marker for meditation. Relative increase in parieto-occipital gamma $(35-45 \mathrm{~Hz})$, decreased frontal delta and increase in frontal theta was reported in meditators performing Vipassana meditation (Cahn, Delorme, \& Polich, 2010).

\subsubsection{Impact of concentrative and mindfulness meditation (combined) on EEG}

A study performed on subjects engaged in transcendental meditation (TM) showed increased alpha band power which is localized over the frontal regions (Takahashi et al., 2005). Higher alpha amplitude and coherence was also observed in subjects performing transcendental meditation (Frederick Travis, 2001). Increased alpha band power and decreased theta band activity was seen in Zen meditators performing abdominal breathing exercise (Yu, X., Fumoto, et.al, 2011). This increased alpha band activity and increase in 
whole blood serotonin level suggested that these might be responsible for improvements of negative mood (Yu et al., 2011). An EEG study on twenty subjects performing TM observed increases in frontal theta power accompanied by increases in frontal alpha and beta power and coherence (Fred Travis et al., 2010). Gamma band activity was also found in studies with beginners and advanced students performing TM (Banquet, 1973).

\subsubsection{Impact of visual color perception on brain activity}

Research to investigate the effect of color on human EEG has become an important research focus, because different colors have different influences on the brain and its findings could provide information for better usability of colors to improve psychological and cognitive functions. Color is the fundamental aspect of human perception (Zhang, H., \& Tang, Z., 2011). Red is experienced as arousing (Elliot et.al, 2007) and is associated with increasing anxiety (Yoto et.al., 2007). Green color is associated with peace and it has a relaxing impact on the behavior of humans (Yoto et al., 2007). Blue color produces cold, passive, quite feelings (Matsuoka, 2000). In a research study involving colored lights, EEG was monitored while a subject was shown different colors on a personal computer screen, and diminished occipital beta activity was observed when subjects was shown a blue color, suggesting that blue may have a more relaxing effect (Ueda Y, 2004).

\subsection{EEG Classification}

In this study, machine learning algorithms were used to classify the EEG signals associated with different meditation types (Walter, Cierniak, \& Gerjets, 2011). Machine learning algorithms were first trained on the training data set to learn distinct patterns in the data and then utilized on the test data to automatically identify patterns in the data (Bishop, 
2006). Distinct patterns mean different features of the data to identify dissimilarities (e.g. red balls and blue balls have distinct colors and so are different and so it's easy to separate them). The higher the probability of identifying distinct patterns, the better is the classification. Different mathematical measures such as accuracy, sensitivity, specificity etc. are used to quantify the ability of machine learning algorithms to distinguish patterns. Accuracy is defined as an ability to correctly predict an outcome as an actual outcome. Sensitivity is the probability/effectiveness of a classifier to identify positive instances.

Machine learning algorithms that are commonly used for classification of data are: Support Vector Machines, K-Nearest Neighbor, Discriminant Analysis, Decision Trees and Ensemble. A detailed description of each of these classifier algorithms is given below

\section{Support Vector Machine:}

The Support Vector Machine (SVM) has been studied extensively for regression, classification and density estimation (Vapnik, 1995). SVM works by creating a hyperplane (a line in 2D, plane in 3D). More formally, a hyperplane is an n-1 dimensional subspace of an ndimensional space, separating the two classes. Good separation is achieved by the hyperplane that has the largest distance to the nearest data points of any classes. The larger the margin (distance of the closest points of each classes from the hyperplane), the lesser is the generalization error. The construction of a hyperplane is given by $w^{\mathrm{T}} \mathrm{x}+\mathrm{b}=0$ ( $\mathrm{w}$ is the vector of hyperplane coefficients, $\mathrm{b}$ is the bias term) so that the margin between the hyperplane and the nearest point is maximum (Guler \& Ubeyli, 2007). The support vectors are the data points that are closest to the separating hyperplane, these points are on the boundary of the slab. Since an SVM enables classification using linear decision boundaries, it 
is known as linear SVM. However, it is possible to create nonlinear decision boundaries, by using the 'kernel trick'. The kernel generally used is the Gaussian or radial basis function (RBF) kernel (Burges, Christopher JC, 1998). A proper kernel function for a certain problem is dependent on the specific data and till now there is no good method on how to choose a kernel function (Cortes \& Vapnik, 1995). Figure 1 shows the working diagram of SVM.

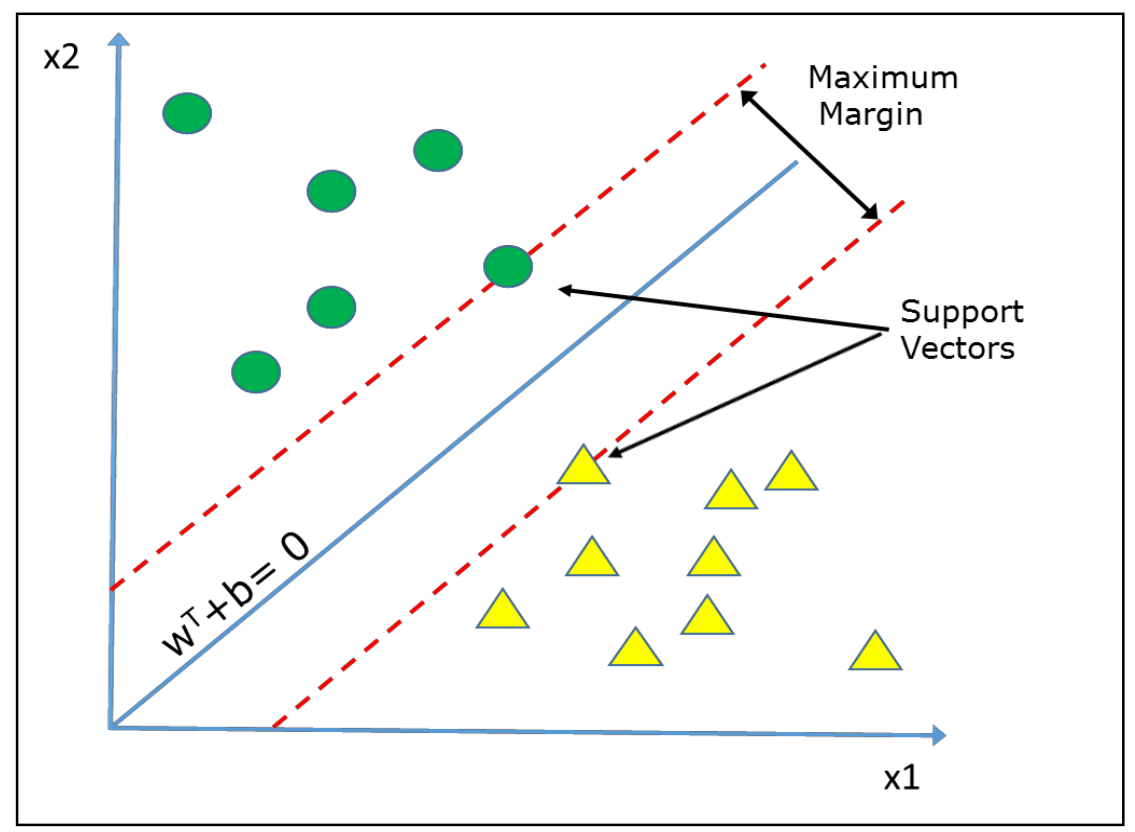

Figure 1: A working diagram of Linear Support Vector Machine (SVM) classifier. Maximummargin hyperplane $\left(w^{T}+b=0\right)$ separating the samples from two classes $(x 1$ and $x 2)$ [diagram modified from https://en.wikipedia.org/wiki/Support_vector_machine]

\section{K-Nearest Neighbor (KNN):}

$\mathrm{KNN}$ is a non-parametric classification technique, to categorize new points based on distances (Boiman, Shechtman, \& Irani, 2008). The aim of this technique is to assign to an unseen point the dominant class among its $\mathrm{k}$ nearest neighbors within the training set (Bishop, 2007). KNN has two parameters that must be set or adjusted, which can in turn, directly affect the classification outcomes. The first one is the number of neighbors $(\mathrm{K})$, while the second one is the distance measure that induces the neighboring relationships 
(Jaskowiak \& Campello,2011). The variety of distance metrics includes 'Euclidean distance', 'Minkowski' and 'Mahalanobis' etc. The number of nearest neighbors ('K value') varies from 1 to 10 , depending on different $\mathrm{KNN}$ models, for achieving maximum classification performance. Figure 2 shows the working diagram of K-nearest neighbor with $\mathrm{K}$ value $=3$

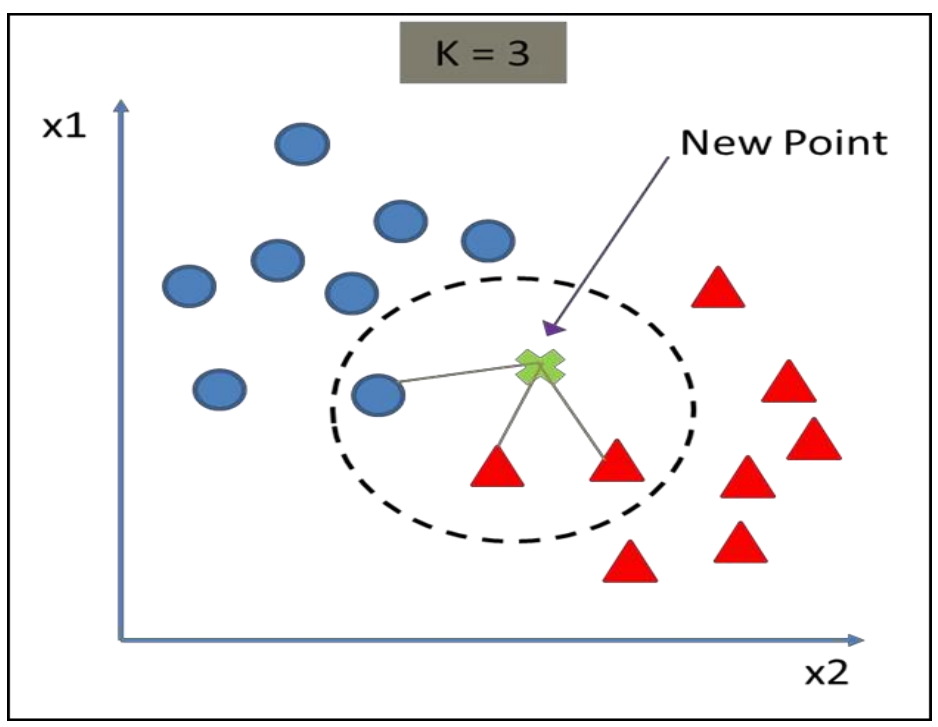

Figure 2: A working diagram of K-Nearest Neighbor (KNN) classifier. [diagram modified from https://en.wikipedia.org/wiki/Support_vector_machine]

\section{Discriminant Analysis:}

Discriminant analysis (also known as Fisher's Linear Discriminant Analysis) was originally developed by (Fisher, Ronald A., 1936). This technique uses a hyperplane to separate the data representing the different classes (Fukunaga, 1990).

\section{Decision Tree:}

A Decision tree is a special type of graph drawn in the form of a tree structure. It classifies data through recursive partitioning of the data set into mutually exclusive subsets 
which best explain the variation in the dependent variable under observation (Biggs, De Ville, \& Suen, 1991). Decision trees classify instances (data points) by sorting them down the tree from the root node to some leaf node. This leaf node gives the classification of the instance. Each branch of the decision tree represents a possible scenario of decision and its outcome.

\section{Ensemble Classifier:}

An ensemble is a combination of several classifiers, aggregated in different ways (Galar, Fernández, Barrenechea, Bustince, \& Herrera, 2011). More recently, there is a significant interest in using ensembles classifier as a way of improving the classification accuracy by many binary classification algorithms to solve a multi-category problem (Dietterich, 2000). It constructs a set of classifiers (like decision trees, discriminant analysis, K-nearest neighbors etc.) and then classifies new data points by taking a (weighted) vote of their predictions. Two of the most popular ensemble methodologies are Bagging (Breiman, 1996) and Boosting (Freund \& Schapire, 1996). Bagging is a procedure of creating bootstrap samples of your dataset and training a model on each using a learning algorithm, then averaging their predictions for an unknown vector. Whereas, boosting is a procedure that combines many weak classifiers (like SVM, nearest neighbor etc.) to produce a powerful-ones.

Properties of different classifier (Lotte et.al., 2007) are:

(1) Generative classifier: A classifier, in order to classify a feature vector, computes the likelihood of each class and chooses the most likely.

(2) Discriminative classifier: A classifier which directly discriminates the feature vector into classes. 
(3) Static classifier: A classifier which does not take into account the temporal information during classifying a feature vector.

(4) Dynamic classifier: A classifier which take into account the temporal information during classifying a feature vector.

(5) Stable classifier: A classifier is said to be stable if small variations in the training set do not considerably affect their performance.

(6) Unstable classifier: A classifier is said to be unstable if small variations in the training set do considerably affect their performance.

Regularized: A classifier is said to be regularized if it can control the complexity of classifier in order to prevent overtraining.

\begin{tabular}{|c|l|l|l|l|l|l|l|}
\hline & Generative & Discriminative & Static & Dynamic & Stable & Unstable & Regularization \\
\hline Discriminate Analysis & & & & & & & \\
\hline Decision Tree & & & & & & & \\
\hline Support Vector Machine & & & & & & \\
\hline K-Nearest Neighbor & & & & & & \\
\hline Ensemble methods & & & & & & \\
\hline
\end{tabular}

In this study, we have used support vector machine as a classifier because this classifier has been used in various EEG studies and also because of its good generalization property (Bennett, K. P., \& Campbell, C., 2000). Good generalization property is an ability of the classifier to control the complexity of the classifier, which makes it easier to interpret. Lesser complex classifiers are more stable and hence a small variation in the training set would not affect the performance of the matrix (Lotte et al., 2007). Since the data is highly 
dimensional, it is likely that the training set may be over-trained and hence a classifier like SVM, which is robust to the dimension of the matrix is used (Suykens, Vandewalle, \& De Moor, 2001) 


\section{Chapter 3 METHODS}

This chapter addresses the study designs, experimental protocols, and methods for collecting the EEG, pulmonary and cognitive data during Preksha meditation.

\subsection{EEG Data Collection}

\subsubsection{Participants}

Thirteen novice participants (10 Females, 3 Males, 18-49 years, Mean age: 27.38yrs, SD: 8.54) were recruited by Department of Religious studies at Florida International University (FIU). The inclusion criteria included participants being a university student. All the participants consented for this study which was approved by FIU's investigational review board committee. All the participants meditated for the same duration and in the same room with dim lights for the study. The data for two subjects was not included in the analysis because some of their data files were not usable.

\subsubsection{Participants Preparation:}

Once the participants entered the lab for meditation, a checklist which consisted of information of the participants like subject ID, head circumference, cap size etc. was completed. The participants were then asked to sit quietly in a back rested chair with their feet placed on the foot-pad. A 64-channel Ag/Ag-Cl electrode cap (10/20 configuration) was placed on their scalp based on their head circumference with ground electrode on the midforehead. The ground electrode was used to minimize the leakage current flowing through the participants via the recording system. The EEG cap was then connected to a TMSi amplifier. The 64 electrodes of the EEG cap were then gelled using a mixture of ECI electrogel and signa gel (1:3) to provide conductance between the electrode and the scalp. We kept the electrode impedances between $0-86 \mathrm{~K} \Omega$, by clearing the scalp hair underneath 
the electrode using wooden sticks. However, the impedances for two subjects in the post studies for either $\mathrm{Cz}$ or $\mathrm{CP} 3$ electrode was not getting lowered and so it was kept at a maximum value of $256 \mathrm{~K} \Omega$. The digitization rate was 512 samples per second.

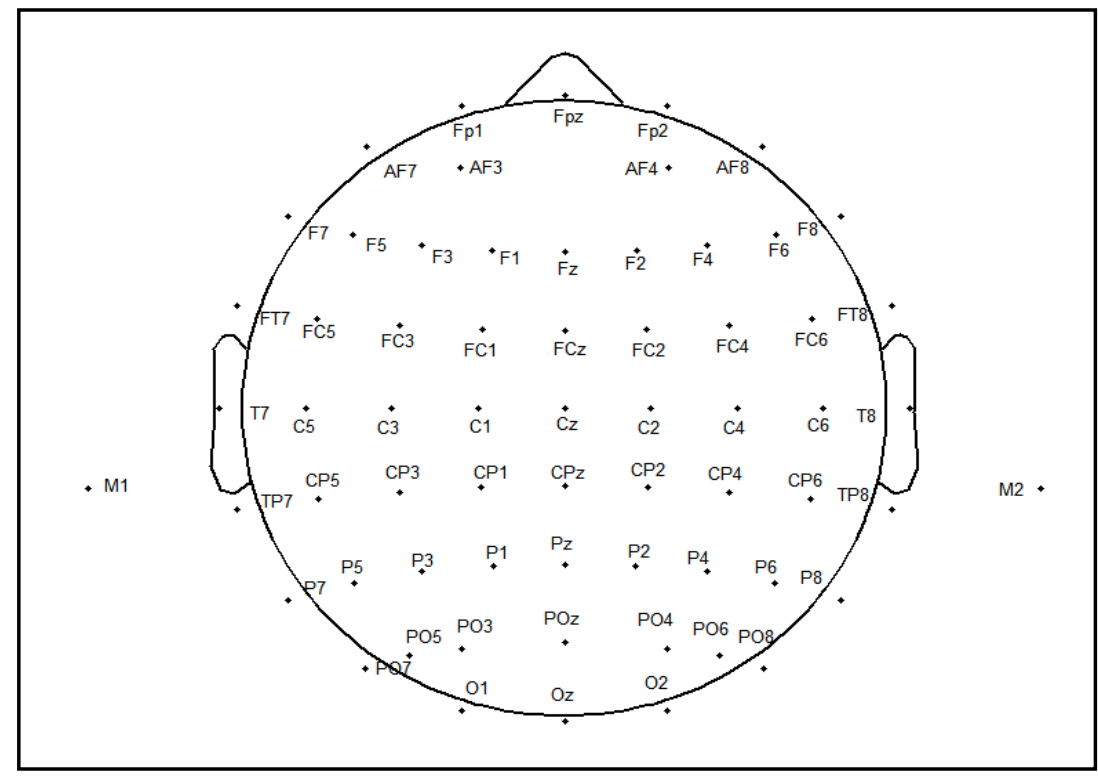

Figure 3: A 2D montage of EEG cap displaying all the electrodes (EEGLAB GUI Interface)

\subsection{3. $\quad$ EEG recording}

The EEG data was recorded twice, once before an eight-week intervention period called 'Pre EEG' and once immediately after an eight-week intervention period called as' Post EEG'. The intervention period included three meditation session, every Monday, Wednesday and Thursday for a total of eight weeks.

\section{Pre EEG test}

Meditation intervention period ( 8 weeks - thrice a week-M,W,T)

\section{Post EEG test}

Figure 4: EEG routines implemented throughout the study 


\subsubsection{Meditation Procedure}

Once the setup was complete a guided audiotape (Figure 6) with instructions was played. First, the EEG recording was started and after a time delay (30 secs- Pre EEG \& 120 secsPost EEG) the audiotape was played in order for participants to get used to the experimental setup and be prepared for meditation. The audiotape was divided into three different stages: (1) Relaxation phase, (2) Buzzing meditation and (3) Green color meditation. During the relaxation phase, the participants were asked to sit silently with eyes closed for a minute. There are two relaxation phases, one immediately at the start of the audio named 'Relaxation (start)' and another at the end of the audio named 'Relaxation (end)'. After the relaxation (start) phase, the participants used the buzzing technique of Preksha meditation, which involves producing a vibrating humming sound imitating the buzzing of bumblebees with their lips and eyes closed. This buzzing meditation was further subdivided into two types, one focusing the attention on the center of the brain while performing the humming activity and other focusing the attention only on the humming activity. The third stage of the audio file was Green color meditation, which was subdivided into three types: Green meditation, where the participants were asked to visualize anything which is of green color with their eyes closed. They were also asked to visualize that everything surrounding them is green in color and they are seated in a beautiful green environment. Green breath meditation, where the subjects perform normal breathing, imagining inhalation of green color and exhalation of toxic contents from the body. Finally, the Green heart chakra meditation, where they were told to focus on the fourth energy center (also called as psychic center) of the body. In this meditation type, they are asked to visualize the green light glowing at this energy center. The same audio file was played during the entire intervention period of eight weeks. 


\subsection{Data Processing and Analysis:}

\subsubsection{Software Used:}

EEG data was collected using Advance Source Analysis (ASA) software (ANT-Neuro, Netherlands). EEGLAB (Delorme \& Makeig, 2004) running under a platform MATLAB environment (The Mathworks, Inc.) was used for offline analysis of EEG data. Classification learner application of MATLAB, was used to classify the high dimensional EEG signals.

\subsubsection{EEG signal processing:}

The 64-channeled EEG data were bandpass filtered from $0.1 \mathrm{~Hz}-120 \mathrm{~Hz}$ using a sinc FIR filter windowed with a Blackman window function. To remove the electrical interference at $60 \mathrm{~Hz}$ and its harmonics, a regression-based approach (Mitra \& Bokil, 2009) as implemented in the Cleanline EEGLAB plugin (Bigdely-Shamlo et.al., 2015) was used. Artifacts were rejected from all the 64 channels using a threshold technique, where segments of data exceeding $+/-80 \mu \mathrm{V}$ were rejected and replaced with zeros (zero-padded). The electrodes were then referenced to the average of data from the linked mastoid location electrodes. Power spectral density $\left(\mu \mathrm{V}^{2} / \mathrm{Hz}\right)$ was calculated for artifact free data using a Welch Periodogram (Welch, 1967) with Hanning window of length 4secs (frequency resolution: $0.25 \mathrm{~Hz})$ and an overlap of $50 \%$. The relative power in each individual band, delta $(1-4 \mathrm{~Hz})$, theta $(4-8 \mathrm{~Hz})$, alpha $(8-13 \mathrm{~Hz})$, beta $(13-40 \mathrm{~Hz})$ and gamma $(40-100 \mathrm{~Hz})$ were computed by dividing the power in each band by the total power in the frequency range $(1-100 \mathrm{~Hz})$ for each channel. The block diagram of data processing is shown in Figure 8. 
In order to classify these EEG band powers underlying different forms of Preksha meditation, a machine learning approach (classifier) was undertaken. Figure 5 shows the different combinations of channels and bands that were used as predictors to the classifier. The idea of selecting different combination of channels and bands were to reduce the dimensionality of matrix and also to find some significant features/ predictors that produce higher classification accuracy. Initially the entire dataset, All ( 5 band $* 62$ channels $=310$ predictors) were used as input to the classifier for both sessions - Pre and Post. Similarly, delta $(1$ band $* 62$ Channels $=62$ predictors $)$, theta $(1$ band $* 62$ Channels $=62$ predictors $)$, alpha $(1$ band $* 62$ Channels $=62$ predictors $)$, beta $(1$ band $* 62$ Channels $=62$ predictors $)$ and gamma ( 1 band $* 62$ Channels $=62$ predictors $)$. Figure 7 shows the detailed step-by-step description of how the data (All) was processed in machine learning. The data were fed into the classifier and the accuracy was noted down each time the classifier was implemented. This procedure was iterated for a total of 10 times so that the classifier can learn more

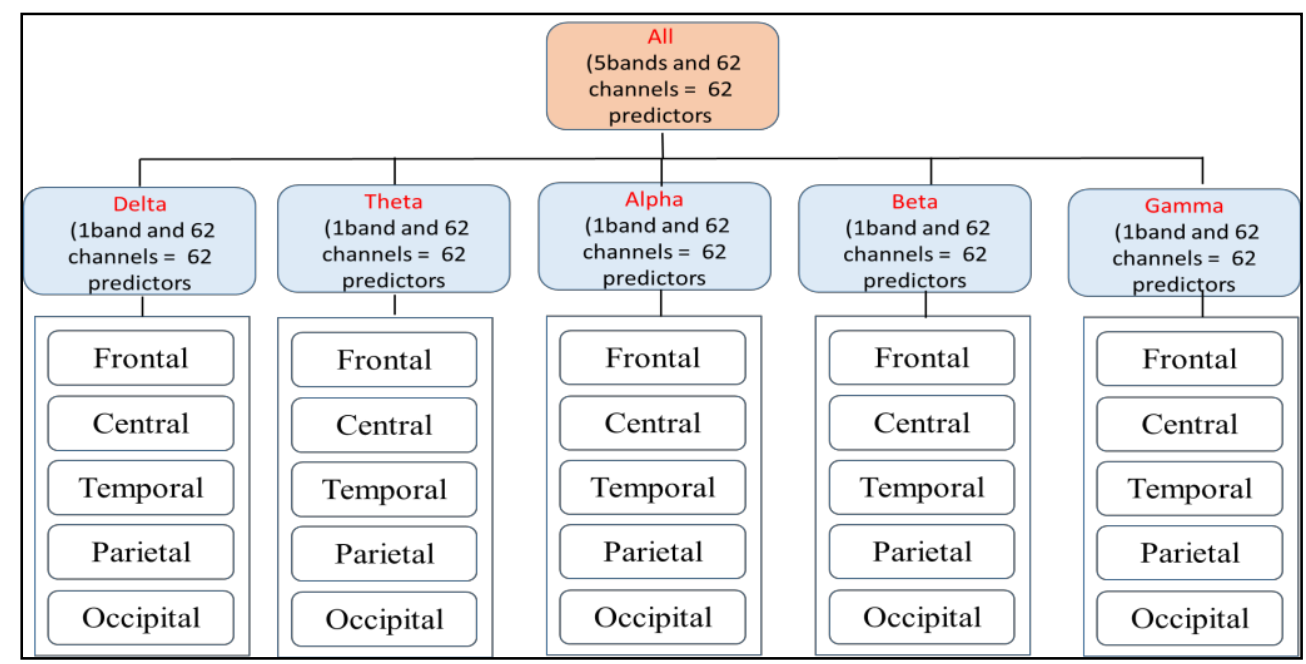

Figure 5: Different combinations of channels and bands 
diversity (every iteration different training and testing data are taken into account), each time, and provide better. classification. However, there is no specific literature stating the number of iterations a classifier can be implemented on the data for better classification, so in this study, we have randomly used 10 iterations. The mean accuracy for all the 10 iterations was used, as a measure, to understand which predictor is better able to classify meditation groups.

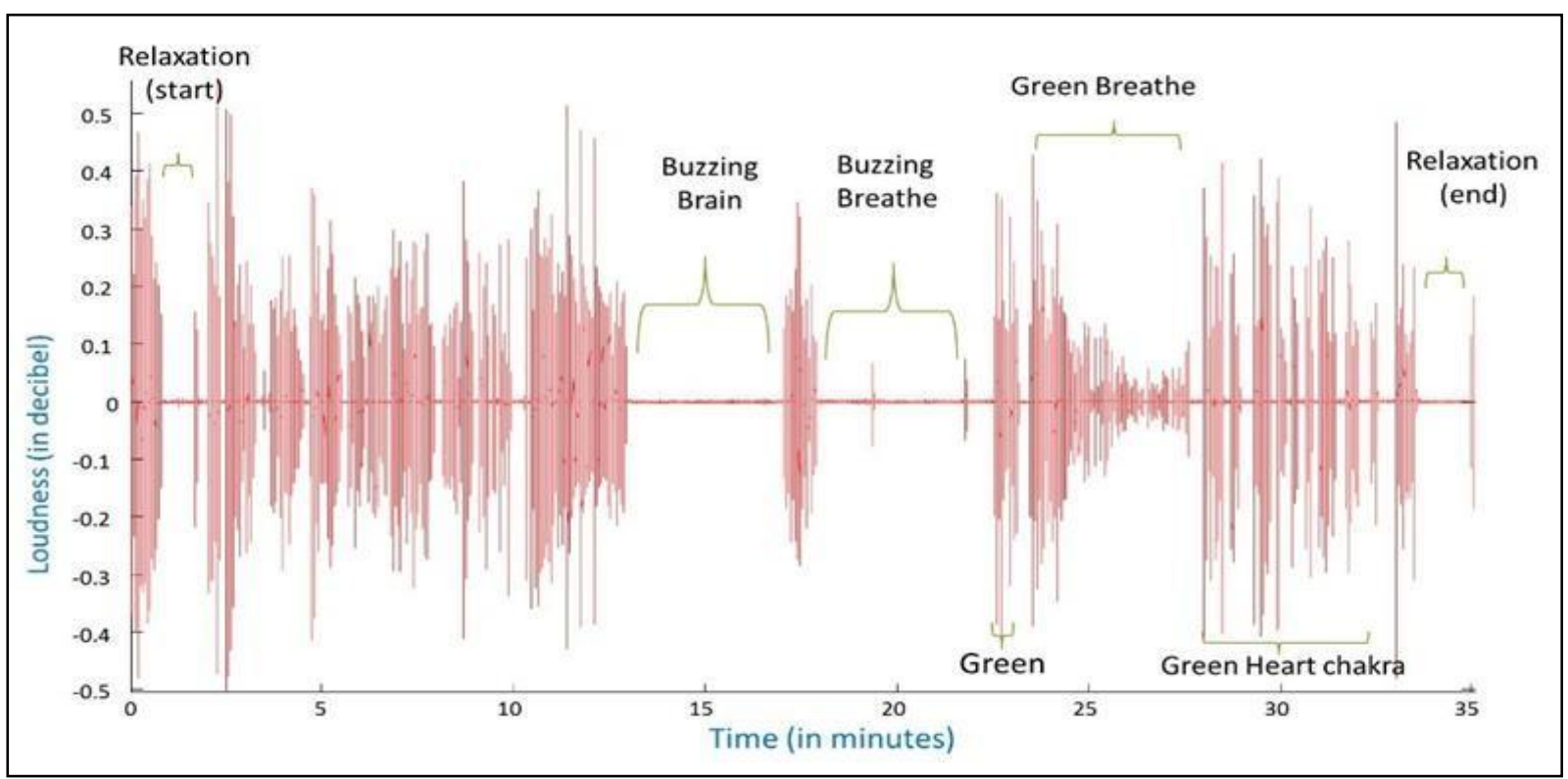

Figure 6: Signal representation of Audio File.

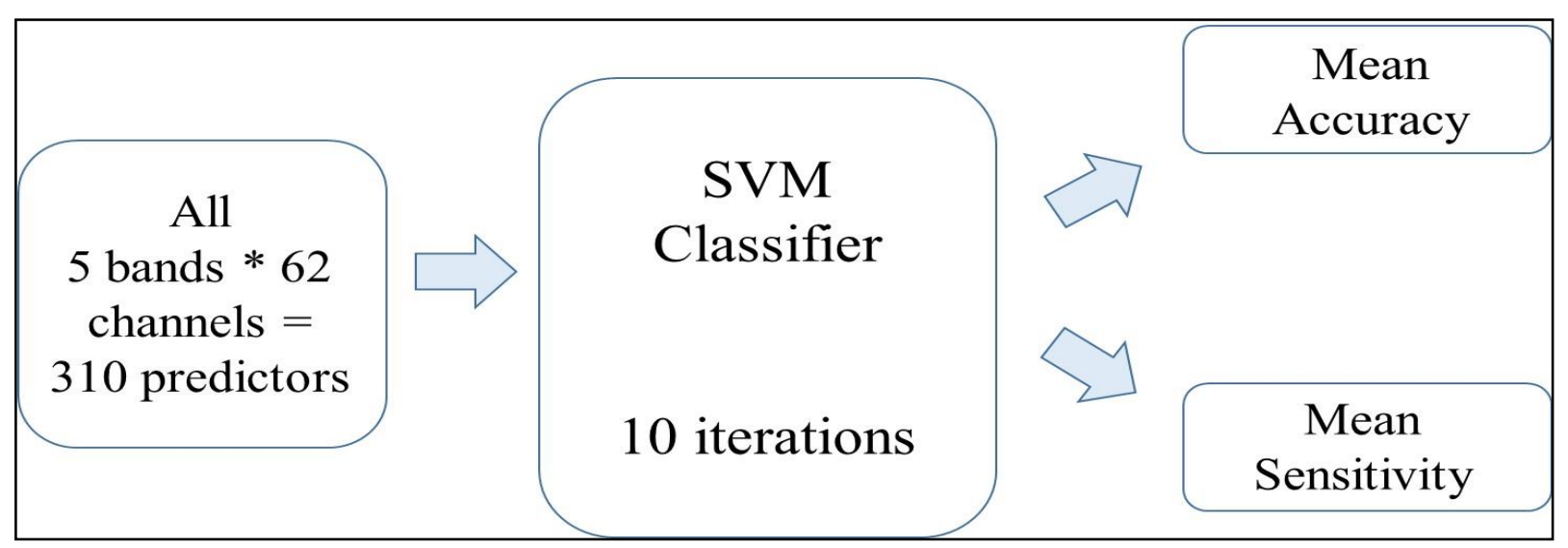

Figure 7: Description of how data, all was processed in Machine Learning. 


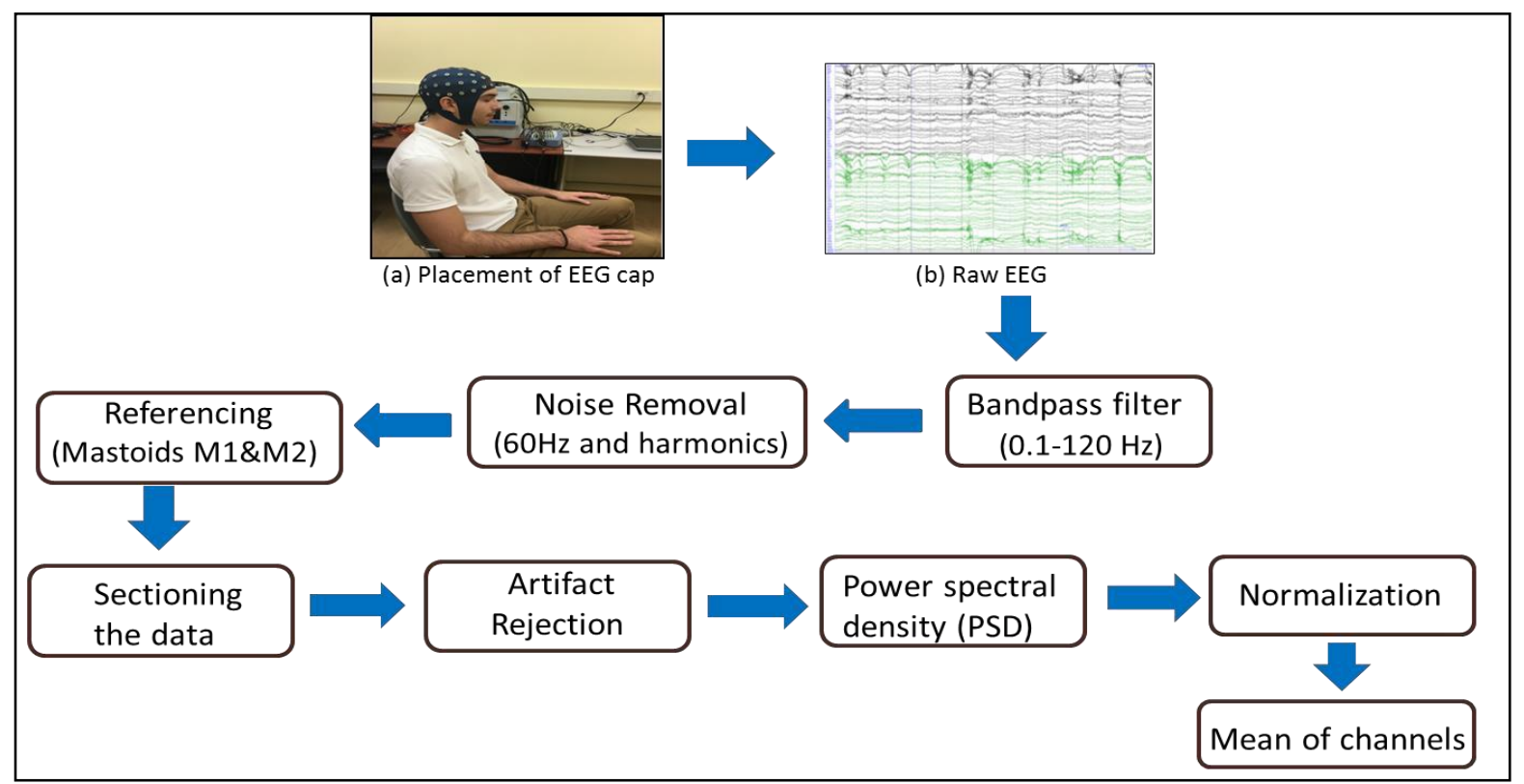

Figure 8: Complete block diagram of data processing. (a) Placement of EEG cap on the subject's scalp. (b) The view of raw EEG of the subject recorded during meditation

\subsection{Pulmonary Assessments}

Pulmonary assessment tests were performed to measure the volume of air inspired and expired by the lungs. The parameters assessed included forced expiratory volume (FEV), forced vital capacity (FVC), using an NDD EasyOne Frontline Spirometer. FEV measures how much air a person can exhale during a forced breath. The amount of air exhaled may be measured during the first (FEV1), second (FEV2) and /or third (FEV3) second of the forced breath. FVC is the total amount of air exhaled during the FEV test. The participants were requested to place the spirometer in their mouth with the tongue under the mouthpiece and to close their lips tightly around the mouthpiece and instructed to take a deep breath, close their eyes, and emit a humming noise for as long as they could on the one breath. Peak 
expiratory Flow (PEF), which is a person's maximum speed of expiration was measured using a Microlife PF 100 digital peak flow meter. These measures were taken 5 times and the three best were taken into consideration.

\subsection{Cognitive Assessments}

Two types of cognitive assessment tests were evaluated to see the improvement in mental processes of subjects engaged in short eight weeks of Preksha meditation.

\subsubsection{Memory test}

A memory test was performed using Automated Working Memory Assessment (AWMA), a computerized tool for assessing short-term and working memory. AWMA is designed to provide a practical and convenient way for teachers or researchers to screen their subjects for significant working memory problems with a friendly interface. Two types of short-term verbal memory tasks were performed. 1. Digit Recall and 2. Word Recall. In the digit recall test, subjects have to listen to a sequence of numbers and have to recall each sequence in the correct order. Word recall is the same as digit recall, only difference is words are listened and recalled instead of numbers. Two types of verbal working memory tasks such as listening recall and listening recall processing were performed. In listening recall, he/she (subjects) hears a series of spoken sentences and has to verify 'true' or 'false', also he /she needs to recall the final word for each sentences in a sequence. In listening recall processing, a measure of how fast the responses were made in the listening recall task. In the Spatial Recall test, a series of shapes requiring individuals to mentally manipulate the objects and remember the placement of a sequence of shape. In the Spatial Recall processing, a measure of how fast the responses are made in the Spatial Recall test is assessed. 


\subsubsection{Positive Affect and Negative Affect Schedule (PANAS) test:}

The PANAS is a 20 -item self-report measure of positive and negative affect (Watson, Clark, \& Tellegen, 1988). It is a test to study human emotion and is obtained by self-reports from participants to quantify their feelings or emotions (positive or negative) over a period of time (i.e. experiment time). 20 -items were segregated into 10 positive feelings (or emotions) and 10 negative feelings (or emotions). Emotions such as excited, interested, strong, alert, enthusiastic, proud, inspired, determined, attentive and active are considered as positive whereas, distressed, afraid, jittery, nervous, ashamed, irritable, scared, hostile, upset and guilty are considered as negative (Crawford \& Henry, 2004). After completion, the subjects are told to rate each of this emotions which they have experienced within that specified time on a 5-point scale. The scale points are: 1. 'very slightly or not at all', 2. 'a little', 3. 'moderately', 4. 'quite a bit', 5. 'very much or extremely'.

\subsection{Statistical Analysis}

A Paired Sample t-test was performed for pulmonary function tests, PEF and FEV, cognitive memory test for digit recall, digit recall processing, listening recall, listening recall processing, spatial recall, spatial recall processing, positive and negative subjective measures using SPSS software. Statistical significance of each measure for comparison between the pre (before intervention) and post (after intervention) meditation sessions were evaluated with an alpha level of 0.05 . 


\section{Chapter 4 RESULTS}

\subsection{Electroencephalography (EEG)}

Figure 9 below summarizes the overall accuracy results when different combinations of channels and power bands are applied to the RBF kernel SVM classifier as input. The $\mathrm{x}$-axis consists of all the predictors, while the y-axis shows the accuracy in percent. The predictors (16) are All (310 predictors), All frontal (80 predictors), All central (105 predictors), All temporal (30 predictors), All parietal (45 predictors) and All occipital (50 predictors) respectively. Similarly, predictors (7-12) are for delta, (13-18) for theta, (19-24) for alpha, (25-30) for beta and finally (31-36) for Gamma. According to Figure 9, the overall accuracy of all the predictors varied between 6-12\% in the pre session (Fig 9 (A)), whereas in the post session it varied between 6-13\% (Fig 9 (B)). In order to find the best predictor which is sensitive to each of the classes, we did take into consideration the sensitivity of each class. The sensitivity is the true positive rate (TPR), which is the ratio of positives that are correctly classified to the total positives. In our study, since sensitivity is the ratio of correctly classified class to the total number of classes that are correctly classified, higher the sensitivity, better would be the predictor in distinguishing one class from another. Figure 10 shows the sensitivity plots for different combinations of channels and bands for buzzing brain meditation class in pre session. On the $\mathrm{x}$-axis we have different predictors (or features) and on $\mathrm{y}$-axis, sensitivity in percent. For pre studies, the sensitivity was higher for predictor number 29, Beta parietal. Figure 11 shows the sensitivity of Buzzing breathe meditation in pre session, higher sensitivity is for predictor 1, All. Figure 12 shows a sensitivity plot for green color meditation in pre session. Pre session shows highest accuracy in predictor 1, All Similarly, the sensitivity for post, Figure 13 is higher for predictor Delta Occipital. Figure 14 shows the sensitivity of buzzing breathe 
meditation for post session, it is clear from the figure that the highest sensitivity is for predictor 1, All. and Figure 15 show sensitivity plots for green color meditation in post session, where highest sensitivity is shown for predictor number 19, Alpha.

(A)

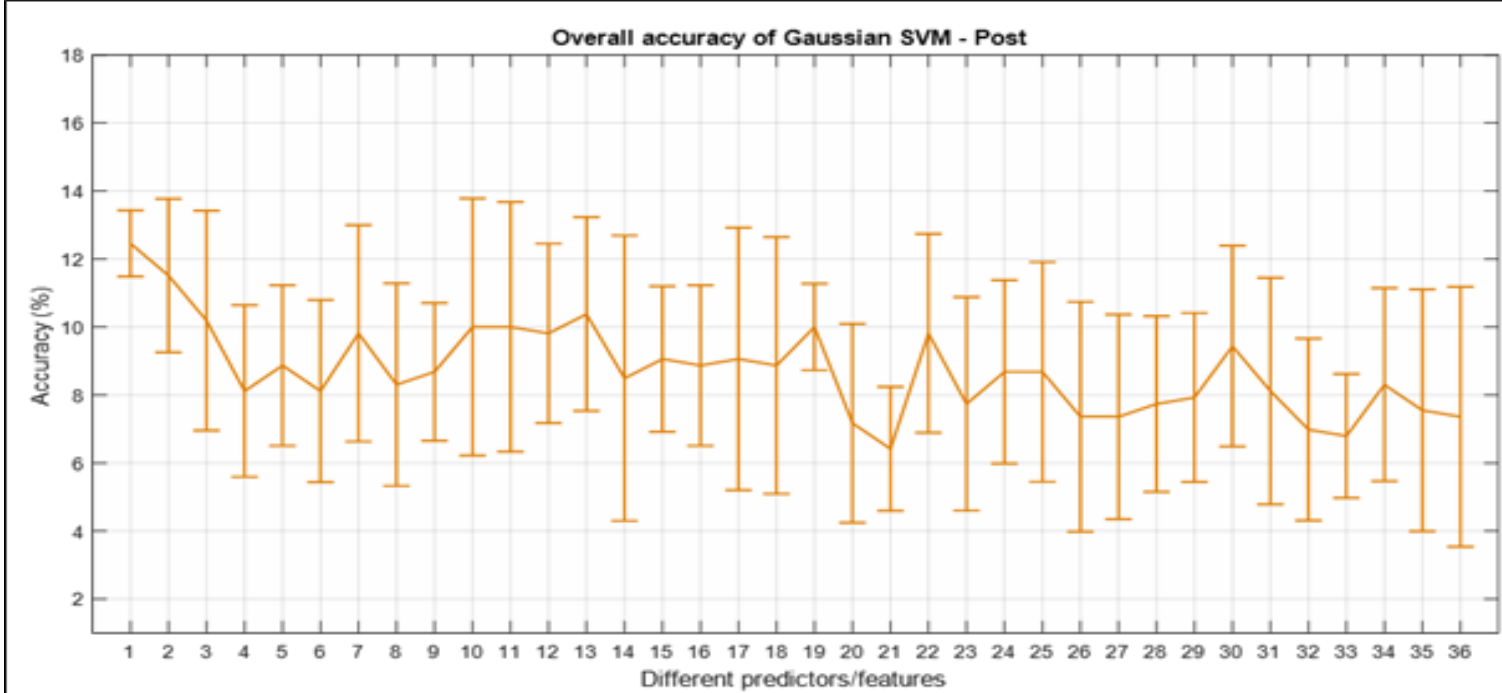

(B)

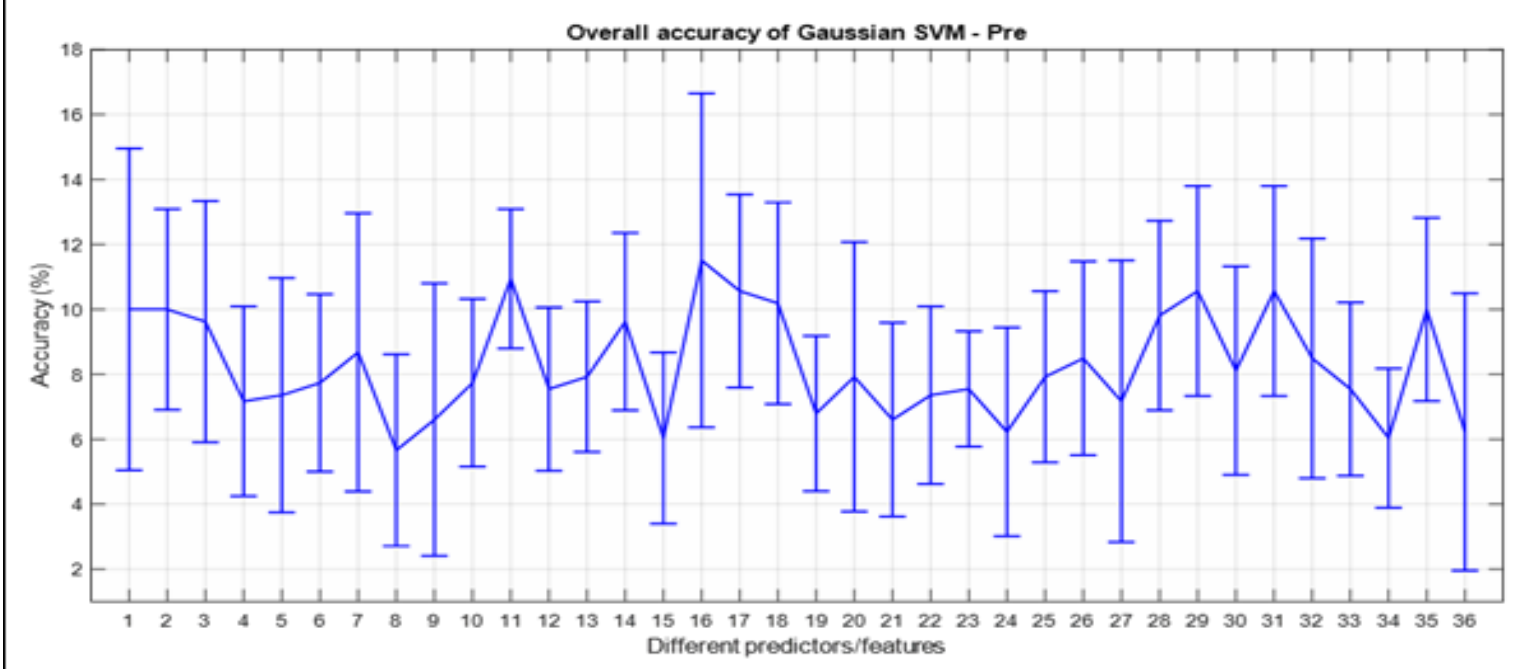

Figure 9: Overall classification accuracy for all the predictors. (A) Classification accuracy in the pre session. (B) Classification accuracy in the post session. 


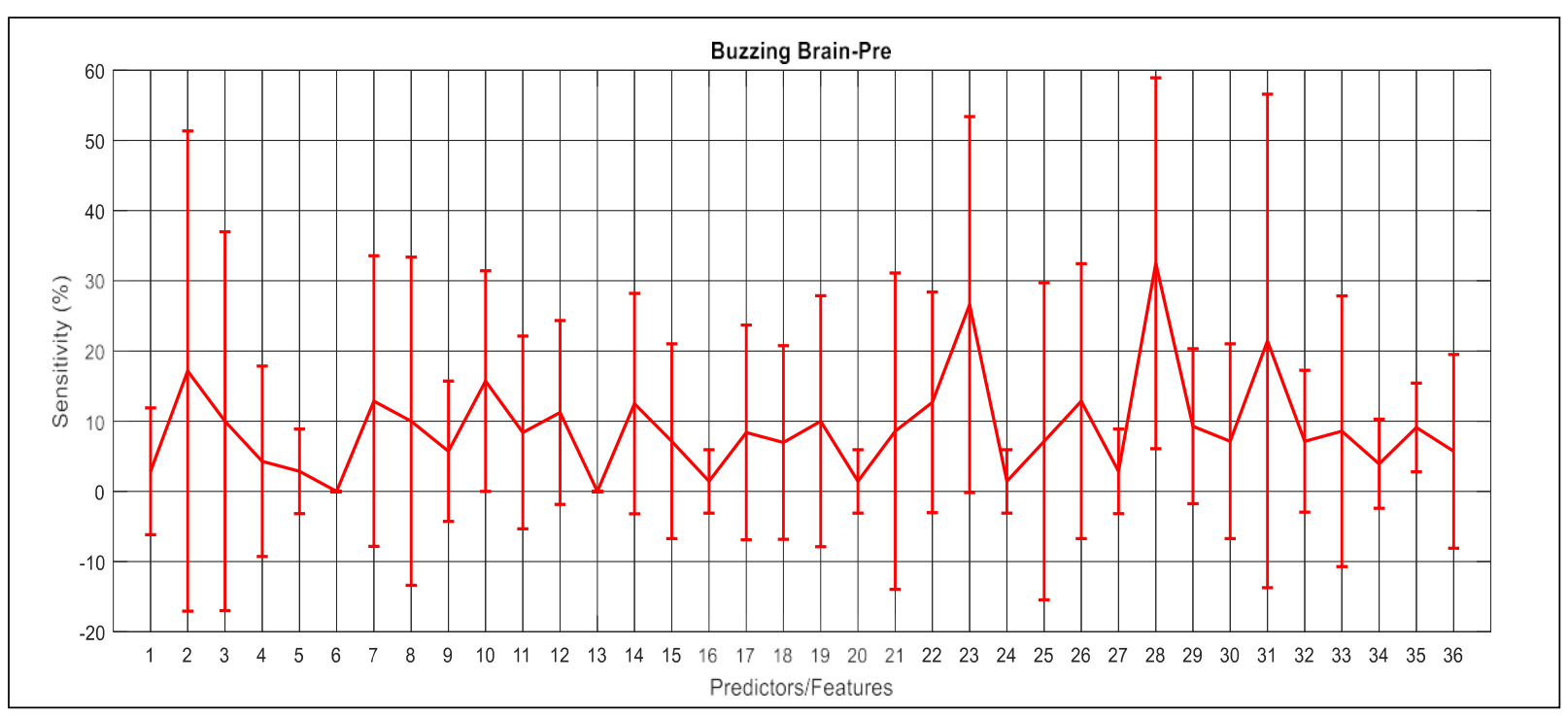

Figure 10: Sensitivity of different predictors for Buzzing brain meditation in pre session

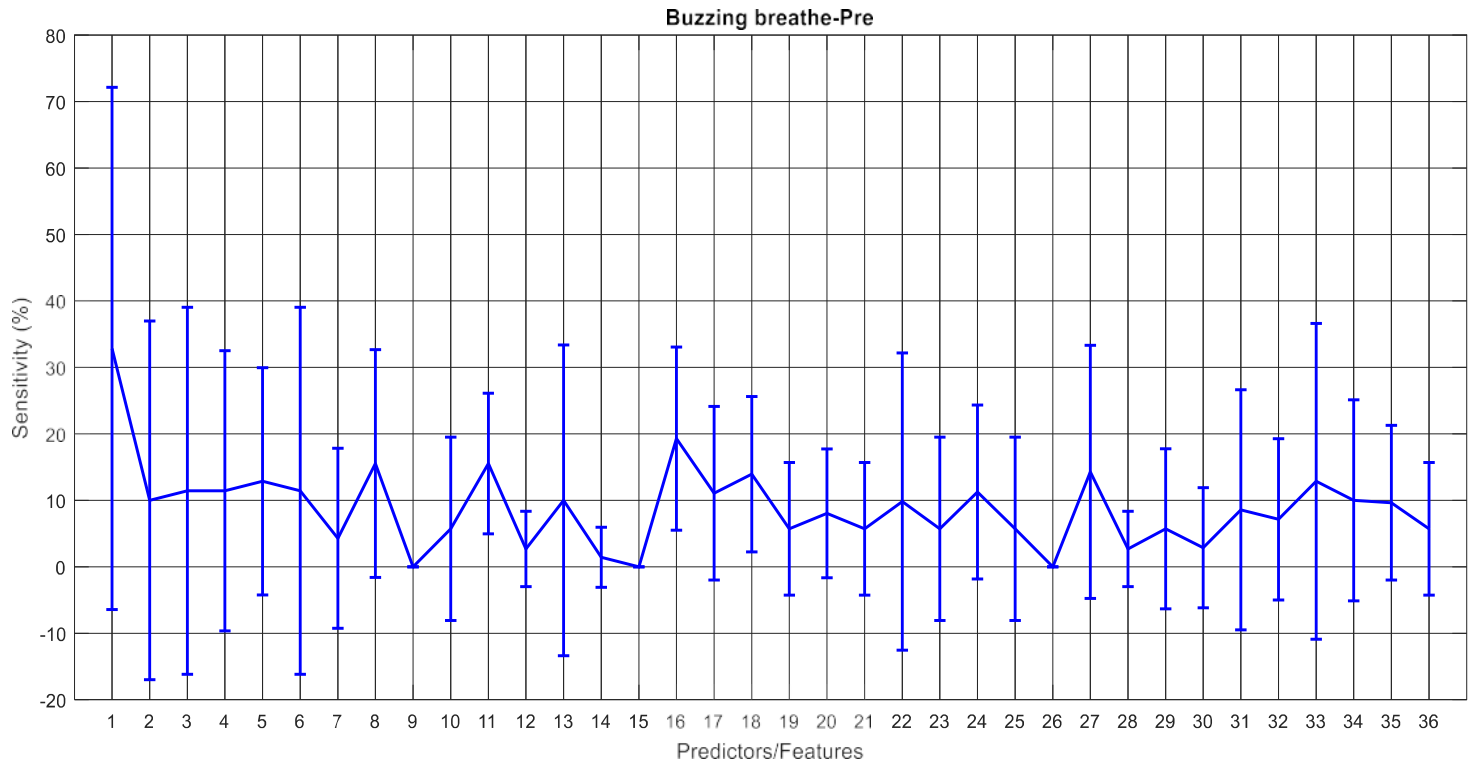

Figure 11: Sensitivity of different predictors for Buzzing breathe meditation in pre session. 


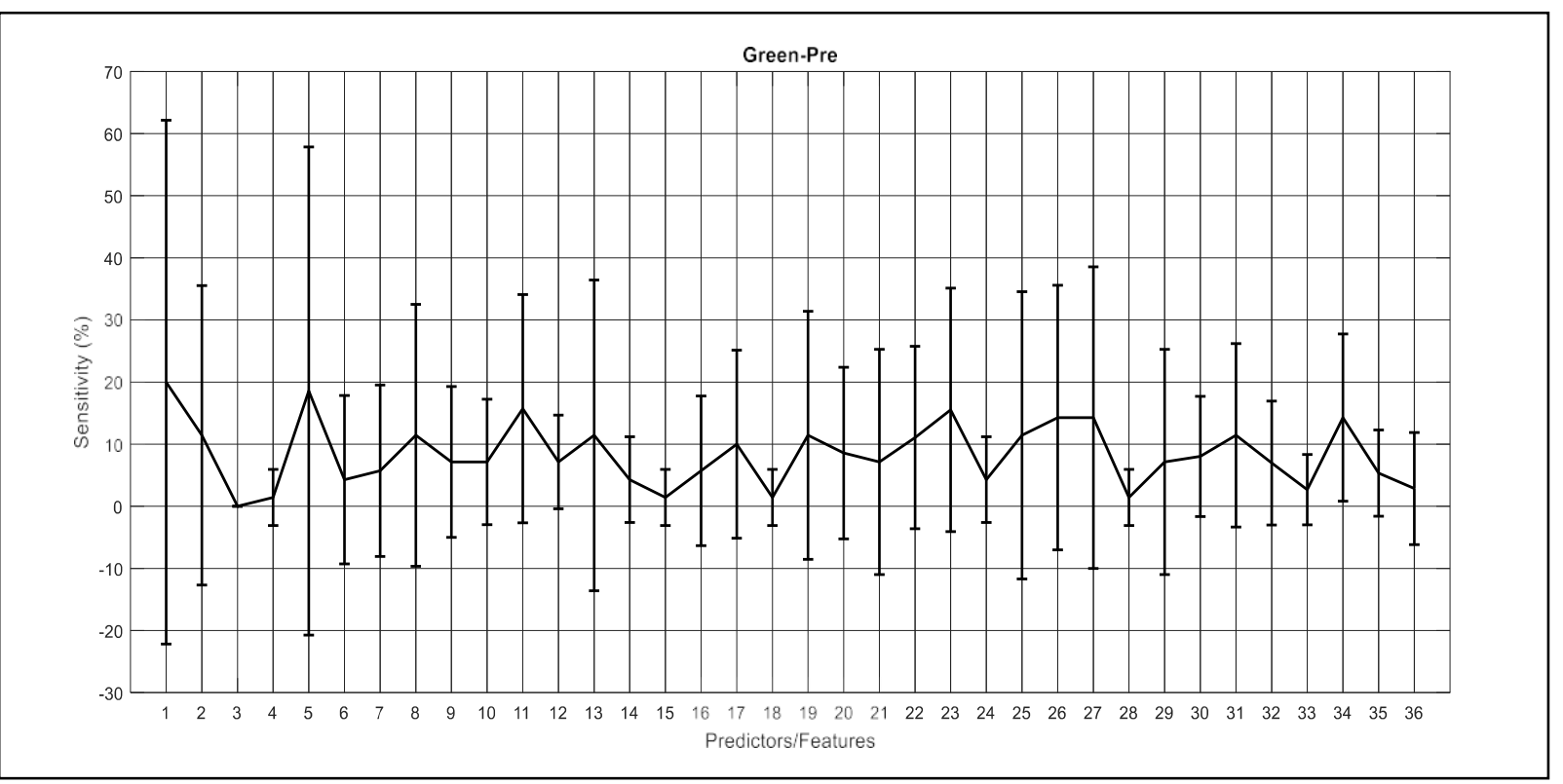

Figure 12: Sensitivity of different predictors for Green color meditation in pre session

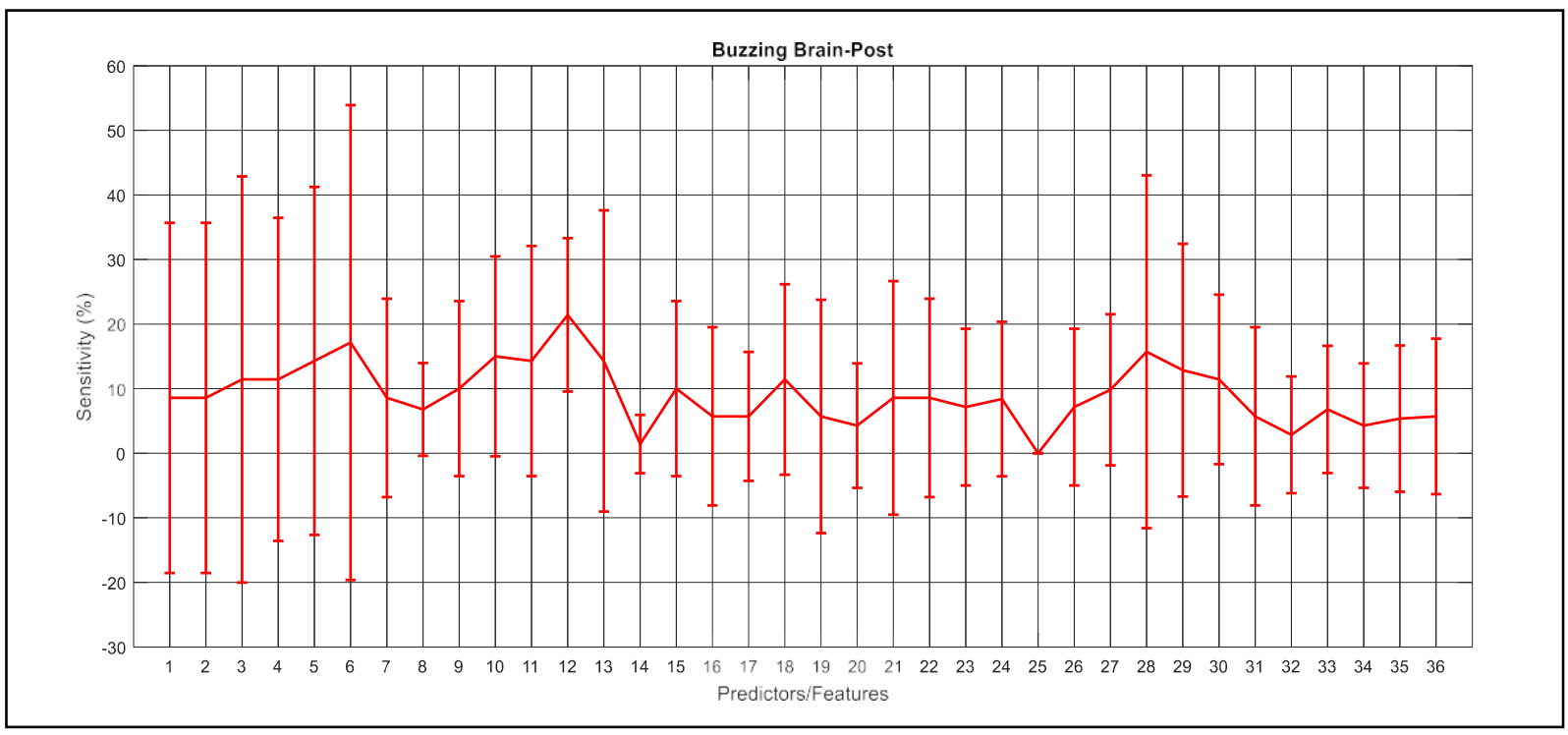

Figure 13: Sensitivity of different predictors for Buzz-brain meditation in post session. 


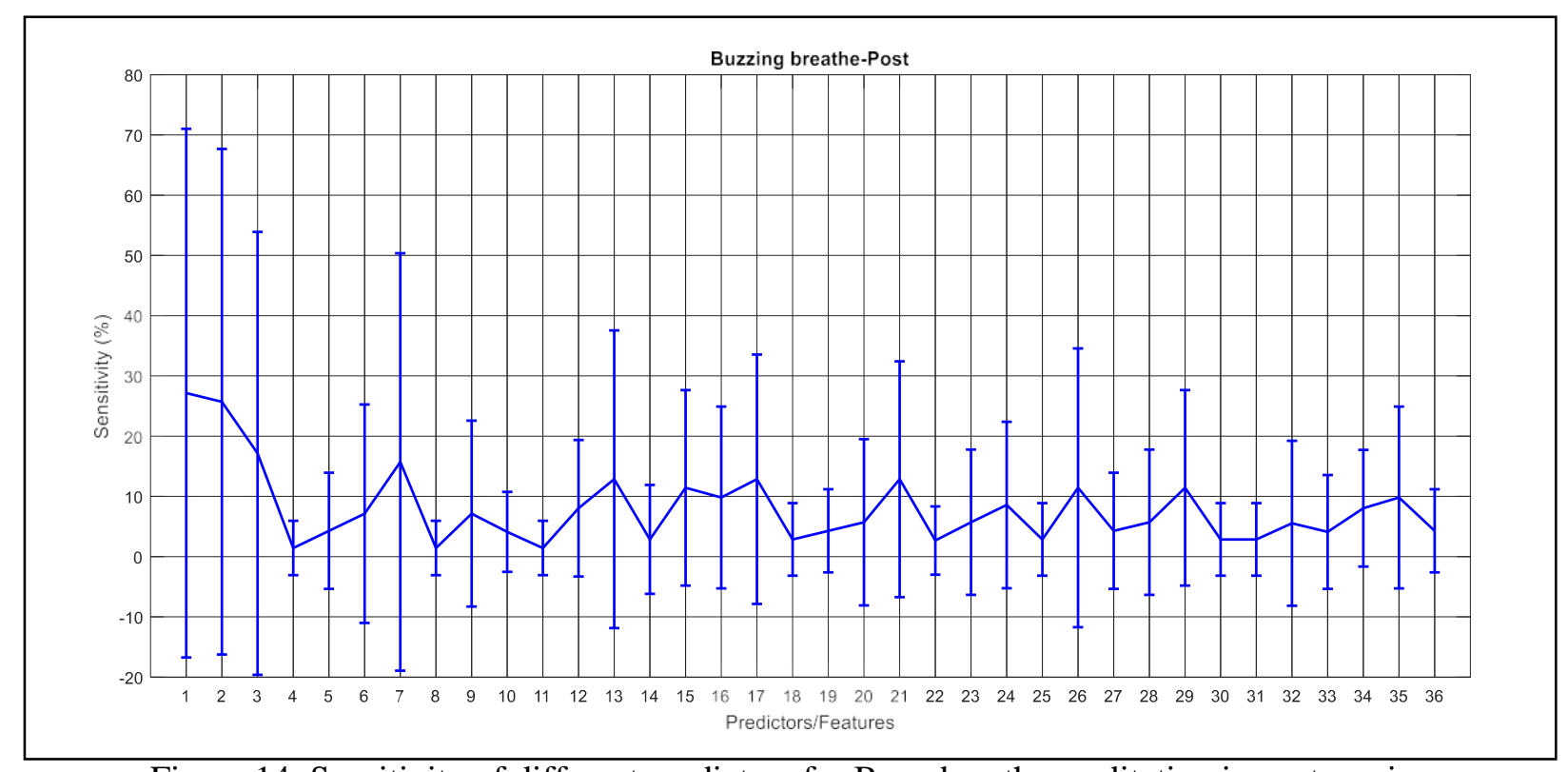

Figure 14: Sensitivity of different predictors for Buzz-breathe meditation in post session

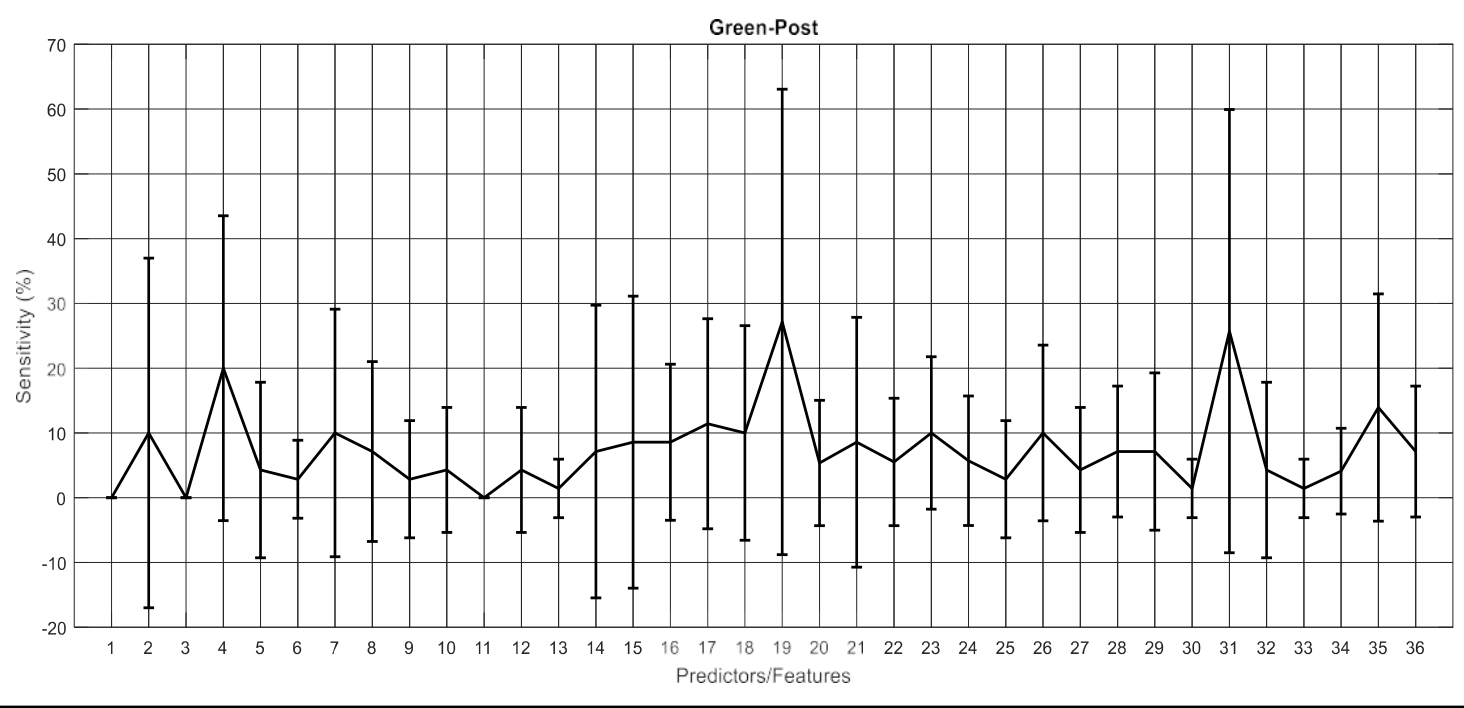

Figure 15: Sensitivity of different predictors for Green color meditation in post session 


\subsection{Pulmonary assessments}

PEF of subjects performing Preksha meditation did not show any significant $(\mathrm{t}=-1.081, \mathrm{p}$ $=0.305)$ increase in the maximum speed of expiration after an eight-week intervention compared to before intervention. FVC of subjects after intervention also showed no significant ( $\mathrm{t}=0.447, \mathrm{p}=0.664$ ) increase compared to before eight-week intervention period. The results indicate that all the measures performed for inspired and expired volume by the lungs were not significant and that Preksha meditation has no effect on the pulmonary function.

\subsection{Cognitive assessments}

\subsubsection{Memory test}

We compared the enhancement in memory performance of subjects performing Preksha meditation before eight weeks compared to after eight weeks using results obtained from digit recall, listening recall, listening processing, spatial recall and spatial recall processing tasks. The raw scores for all the subjects in all the above mentioned memory tasks is shown in Figure 16. There was not a significant $(\mathrm{t}(10)=0.361, \mathrm{p}=0.726)$ increase in the scores for digit recall task, after eight weeks than before eight weeks. There was no significant increase $(\mathrm{t}(10)=0.397, \mathrm{p}=0.700)$ in the scores for listening recall task, after eight weeks than before eight weeks. For listening processing task, no significant $(\mathrm{t}(10)=-0.962, \mathrm{p}=0.359)$ increases in the scores were observed after eight weeks than before eight weeks. There was no significant $(\mathrm{t}(10)=0.844, \mathrm{p}=0.419)$ increase in the scores for spatial recall task, after eight weeks compared to before eight weeks. Also, no significant $(\mathrm{t}(10)=-0.657, \mathrm{p}=0.526)$ 
increase in scores was observed for spatial recall processing after eight weeks compared to before eight weeks for all the subjects. The results here indicate no change was observed in the memory performance of subjects performing Preksha meditation. Figure 17 shows mean and standard deviations of raw scores of subjects performing memory tasks.

\begin{tabular}{|c|c|c|c|c|c|c|c|c|c|c|}
\hline & \multicolumn{2}{|c|}{ Digit Recall } & \multicolumn{2}{|c|}{ Listening Recall } & \multicolumn{2}{c|}{$\begin{array}{c}\text { Listening Recall } \\
\text { processing }\end{array}$} & \multicolumn{2}{c|}{ Spatial Recall } & \multicolumn{2}{|c|}{$\begin{array}{c}\text { Spatial Recall } \\
\text { processing }\end{array}$} \\
\hline & Pre & Post & Pre & Post & Pre & Post & Pre & Post & Pre & Post \\
\hline Subject 1 & 103 & 107 & 101 & 101 & 84 & 85 & 91 & 99.9 & 93 & 98 \\
\hline Subject 2 & 92 & 92 & 84 & 94 & 74 & 83 & 107 & 120 & 104 & 125 \\
\hline Subject 3 & 96 & 82 & 119 & 77 & 80 & 73 & 130 & 86 & 74 & 86 \\
\hline Subject 4 & 126 & 126 & 115 & 101 & 96 & 83 & 81 & 81 & 83 & 84 \\
\hline Subject5 & 82 & 86 & 70 & 80 & 73 & 74 & 72 & 86 & 75 & 86 \\
\hline Subject6 & 101 & 99 & 80 & 91 & 73 & 81 & 99 & 97 & 97 & 96 \\
\hline Subject7 & 73 & 80 & 80 & 112 & 73 & 99 & 107 & 91 & 101 & 94 \\
\hline Subject 8 & 999 & 103 & 88 & 128 & 79 & 106 & 95 & 104 & 94 & 106 \\
\hline Subject 9 & 102 & 86 & 119 & 98 & 98 & 84 & 119 & 111 & 115 & 115 \\
\hline Subject 10 & 94 & 97 & 87 & 101 & 79 & 83 & 107 & 109 & 109 & 108 \\
\hline Subject 11 & 86 & 88 & 101 & 105 & 83 & 84 & 109 & 81 & 109 & 83 \\
\hline
\end{tabular}

Figure 16: Raw scores of all the subjects performing Memory task

\subsubsection{Positive and Negative Affect Schedule (PANAS) test:}

An overall subjective feeling of 'positivity' and 'negativity' from the (1-5) self-report scales were statistically analyzed before and after eight-weeks intervention period of Preksha meditation. Positive feeling (or emotions - Figure 18) and negative feeling (or emotions Figure 19) are further analyzed by analyzing the scores in 10 different moods for each measure for all subjects. A significant increase $(\mathrm{t}(10)=-2.66, \mathrm{p}=0.02)$ in the scores of attentive mood was observed after intervention compared to before intervention, for all the subjects. Also, a significant $(\mathrm{t}(10)=-2.27, \mathrm{p}=0.04)$ increase in the scores of proud mood, was observed after compared to before intervention period for all subjects. There is no significant $(\mathrm{t}(10)=-1.24, \mathrm{p}=0.24)$ increase in the scores for all subjects in excited mood, 
determined mood $(\mathrm{t}(10)=-0.82)$, inspired mood $(\mathrm{t}(10)=-0.88, \mathrm{p}=0.39)$, strong mood, active $\operatorname{mood}(\mathrm{t}(10)=-0.89, \mathrm{p}=0.39)$, alert $\operatorname{mood}(\mathrm{t}(10)=-1.40, \mathrm{p}=0.19)$ after eight-weeks intervention compared to before intervention. For negative feeling (or emotions), a significant $(\mathrm{t}(10)=2.95, \mathrm{p}=0.01)$ increase in the scores of jittery mood, was observed after intervention compared to before for all subjects. There was no significant increase in afraid mood $(\mathrm{t}(10)=$ $0.69, \mathrm{p}=0.50)$, ashamed mood $(\mathrm{t}(10)=-0.55, \mathrm{p}=0.588)$, distressed $\operatorname{mood}(\mathrm{t}(10)=1.29, \mathrm{p}=$ $0.22)$, guilty mood $(\mathrm{t}(10)=-0.55, \mathrm{p}=0.58)$, hostile $\operatorname{mood}(\mathrm{t}(10)=-1.15, \mathrm{p}=0.27)$, irritable $\operatorname{mood}(\mathrm{t}(10)=1.47, \mathrm{p}=0.17)$, nervous mood $(\mathrm{t}(10)=0.787, \mathrm{p}=0.45)$ and scared $\operatorname{mood}(\mathrm{t}$ $(10)=0.60, p=0.55)$ after intervention compared to before intervention period.
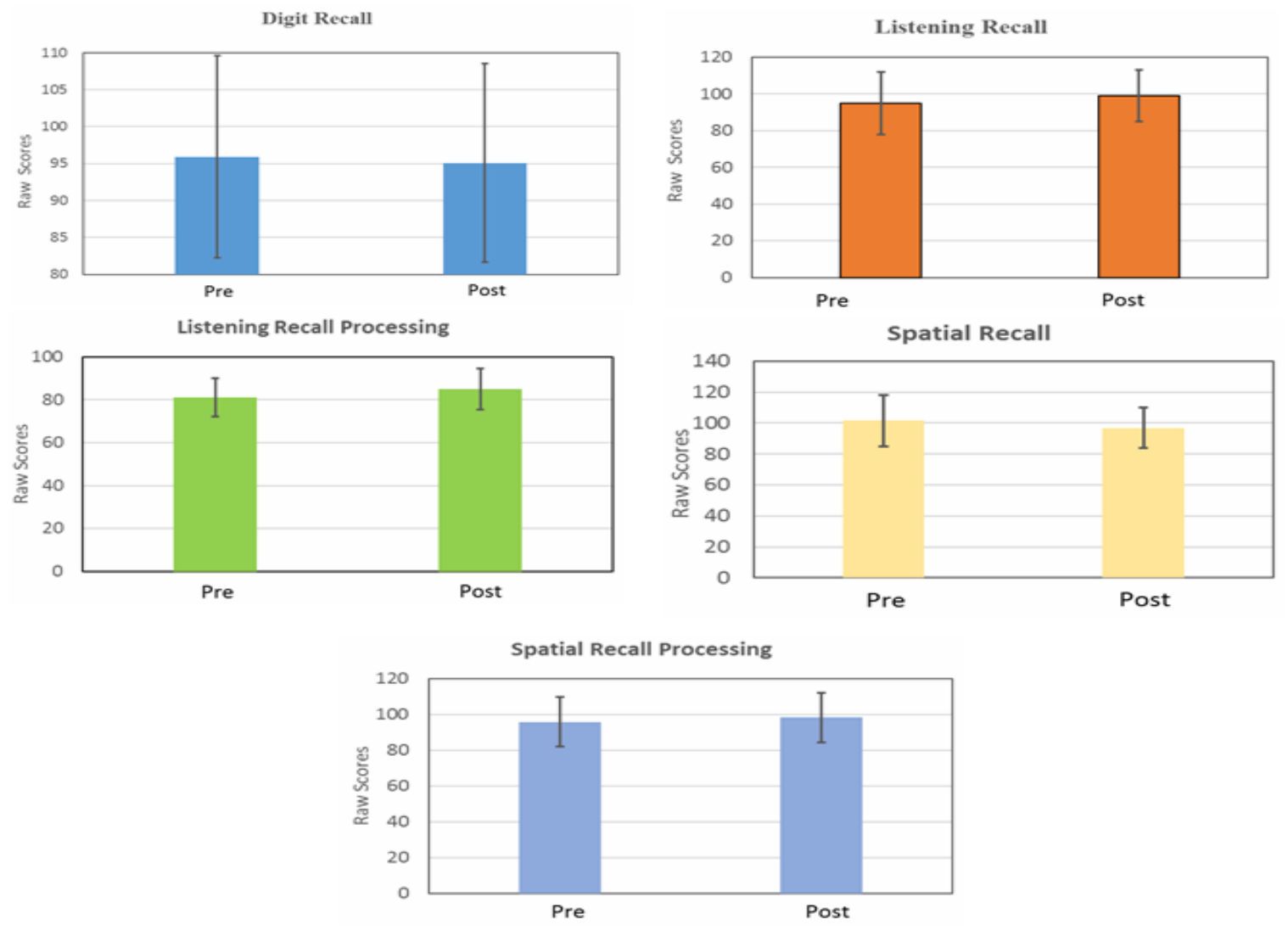

Figure 17: Mean and standard deviation of the raw scores for all the subjects in Memory tasks - Digit Recall, Listening Recall, Listening Recall Processing, Spatial Recall, Spatial Recall Processing. 


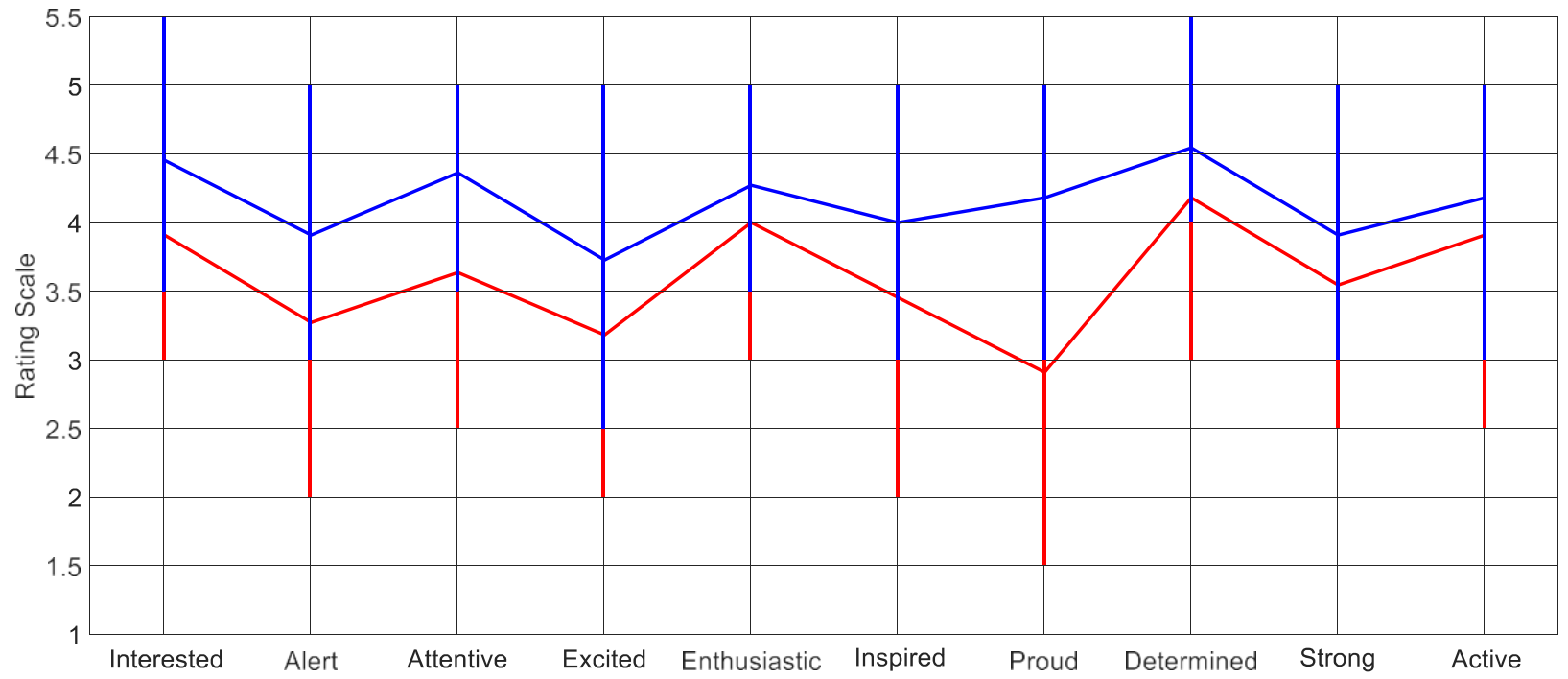

Figure 18: Error bars for each of the 10 positive moods for all the subjects. Blue error bar indicates pre study (before eight-weeks intervention period) and red error bar indicates post study (after eight-weeks intervention period). Star sign indicate that the scores are significantly different at $95 \%$ confidence interval from pre to post for that item.

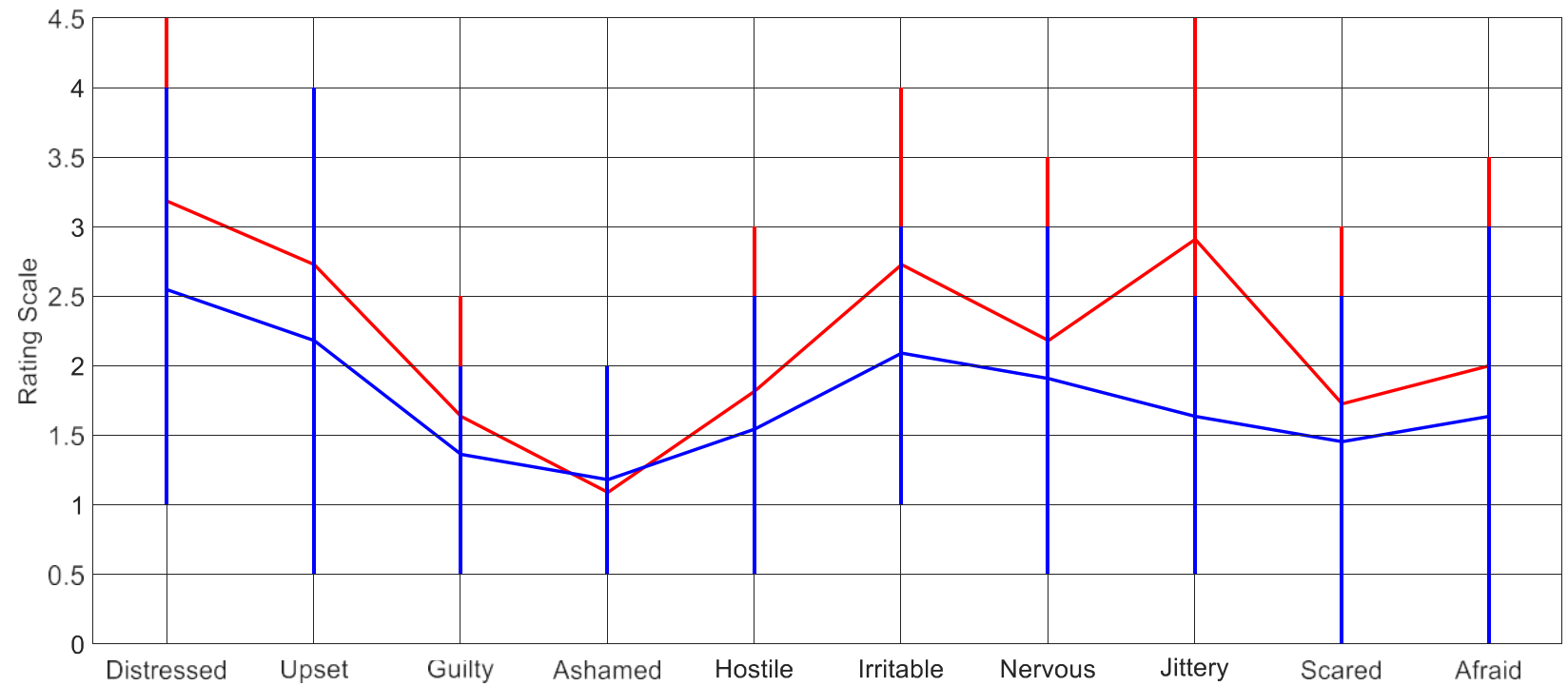

Figure 19: Error bars for each of the 10 negative moods for all the subjects. Blue error bar indicates pre study (before eight-weeks intervention period) and red error bar indicates post study (after eight-weeks intervention period). Star sign indicate that the scores are significantly at $95 \%$ confidence interval different from pre to post for that item. 


\section{Chapter 5 CONCLUSIONS AND DISCUSSIONS}

In this study, we used EEG measures to probe the brain activity underlying Preksha (buzzing and green) meditation. EEG signals of 11 subjects were recorded for 35 minutes and linear features such as band power was extracted and used to identify the mental state associated with different forms of Preksha meditation. A machine learning approach was undertaken, to classify mental states based on the forms of Preksha meditation. The total classification accuracies of RBF-kernel SVM, when different combinations of channels and bands were given as input, were 6-12\% in the pre session, whereas, 6-13\% in the post session. These accuracies are extremely low and none of the predictors in both the sessions are better able to distinguish/classify one meditation type from another. This shows that all predictors are insensitive to the forms of Preksha meditation. We rejected the hypothesis that, theta and gamma band activity, are better able to classify buzzing meditation compared to other meditation types and that alpha band activity is better able to classify green color meditation compared to other meditation types.

Besides EEG, pulmonary measures like PEF, FVC and cognitive measure like digit recall and digit recall processing, listening recall and listening recall processing, spatial recall and spatial recall processing, showed no significant observations in all subjects performing eight weeks of Preksha meditation. The subjective measure, PANAS test showed only significant changes in attentive and proud (positive), and jittery (negative) mood. These findings, also suggest that different participants would have different response to different forms of meditations and this particular form of Preksha meditation, short bouts of buzzing and green color meditation in quick succession, in general, have no effect on the physiological and 
psychological aspect of humans. We cannot find comparisons of our results with previous reports specific to Preksha meditation, as to the best of our knowledge no previous scientific investigation of this technique using EEG has been published. It is also important to note that in this study, we have used linear features of EEG, combination of band powers, which had no considerable changes in the accuracy of classifiers and hence, this feature would not be the best representative in classifying mental states associated with different forms of meditation. It would be worth looking at the non-linear EEG features which showed significant improvement in the accuracy of classification compared to linear features (Hosseinifard, Moradi, \& Rostami, 2011). Also, only the amplitude of the band powers was taken into consideration. In order to measure the flow of information between two electrodes, it would be worth looking at the phase of EEG. Also in this study, only accuracy is used as the parameter to test the performance of classifier, which may not necessarily be an indicator of classifier performance (Fernandes et al., 2010). So it would be worth looking for parameters like sensitivity, specificity and Receiver Operating Characteristic (ROC) plots, which will provide a better picture in evaluating the performance and selection of classifiers.

\section{Future Directions:}

Further exploratory analysis points towards experimental design approach, to understand the underlying neural mechanisms involved in buzzing and green color Preksha meditation. A research design with fixed durations (5-7 mins) for all meditation types and a fixed duration resting state (silently sitting with eyes closed, doing nothing for 1-2 min) between meditations should be adopted, it is because fixed durations will allow the analysis between meditation types to be comparable and the resting state will allow us to find out the transition of mental states from one meditation type to other. 


\section{REFERENCES}

Aftanas, L. I., \& Golocheikine, S. A. (2001). Human anterior and frontal midline theta and lower alpha reflect emotionally positive state and internalized attention: High-resolution EEG investigation of meditation. Neuroscience Letters, 310(1), 57-60.

http://doi.org/10.1016/S0304-3940(01)02094-8

Aftanas, L. I., \& Golocheikine, S. A. (2002). Non-linear dynamic complexity of the human EEG during meditation. Neuroscience Letters, 330(2), 143-146. http://doi.org/10.1016/S0304-3940(02)00745-0

Ahani, A., Wahbeh, H., Nezamfar, H., Miller, M., Erdogmus, D., \& Oken, B. (2014). Quantitative change of EEG and respiration signals during mindfulness meditation. Journal of NeuroEngineering and Rehabilitation, 11(1), 87. http://doi.org/10.1186/17430003-11-87

Arambula, P., Peper, E., Kawakami, M., \& Gibney, K. H. (2001). The physiological correlates of Kundalini Yoga meditation: A study of a Yoga master. Applied Psychophysiology Biofeedback, 26(2), 147-153. http://doi.org/10.1023/A:1011343307783

Baijal, S., \& Srinivasan, N. (2010). Theta activity and meditative states: Spectral changes during concentrative meditation. Cognitive Processing, 11(1), 31-38. http://doi.org/10.1007/s10339-009-0272-0

Banquet, J. (1973). Spectral analysis of the EEG in meditation. Electroencephalography and Clinical Neurophysiology, 35(2), 143-151. http://doi.org/10.1016/0013-4694(73)90170-3

Bigdely-Shamlo, N., Mullen, T., Kothe, C., Su, K.-M., \& Robbins, K. A. (2015). The PREP pipeline: standardized preprocessing for large-scale EEG analysis. Frontiers in Neuroinformatics, 9(June), 16. http://doi.org/10.3389/fninf.2015.00016

Biggs, D., De Ville, B., \& Suen, E. (1991). A method of choosing multiway partitions for classification and decision trees. Journal of Applied Statistics, 18(1), 49-62. http://doi.org/10.1080/02664769100000005

Bishop, C. M. (2006). Pattern Recognition and Machine Learning. Pattern Recognition (Vol. 4). http://doi.org/10.1117/1.2819119

Bishop, C. M. (2007). Pattern Recognition and Machine Learning. Journal of Electronic Imaging (Vol. 16). http://doi.org/10.1117/1.2819119

Boiman, O., Shechtman, E., \& Irani, M. (2008). In defense of nearest-neighbor based image classification. In 26th IEEE Conference on Computer Vision and Pattern Recognition, CVPR. http://doi.org/10.1109/CVPR.2008.4587598 
Breiman, L. (1996). Bagging Predictors. Machine Learning, 24(421), 123140. http://doi.org/10.1007/BF00058655

Cahn, B. R., Delorme, A., \& Polich, J. (2010). Occipital gamma activation during Vipassana meditation. Cognitive Processing, 11(1), 39-56.

Cahn, B. R., \& Polich, J. (2006). Meditation states and traits: EEG, ERP, and neuroimaging studies. Psychological Bulletin, 132(2), 180-211. http://doi.org/10.1037/00332909.132.2.180

Cantero, J. L., Atienza, M., Stickgold, R., Kahana, M. J., Madsen, J. R., \& Kocsis, B. (2003). Sleep-dependent theta oscillations in the human hippocampus and neocortex. Journal of Neuroscience, 23(34), 10897-903. http://doi.org/23/34/10897 [pii] ET 2003/12/03

Clarke, A. R., Barry, R. J., McCarthy, R., \& Selikowitz, M. (2001). Age and sex effects in the EEG: Development of the normal child. Clinical Neurophysiology, 112(5), 806814. http://doi.org/10.1016/S1388-2457(01)00488-6

Cortes, C., \& Vapnik, V. (1995). Support-Vector Networks. Machine Learning, 20(3), 273- 297. http://doi.org/10.1023/A:1022627411411

Crawford, J. R., \& Henry, J. D. (2004). The positive and negative affect schedule (PANAS): Construct validity, measurement properties and normative data in a large non-clinical sample. The British Journal of Clinical Psychology, 43, 245-65. http://doi.org/10.1348/0144665031752934

Cui, X., Bray, S., Bryant, D. M., Glover, G. H., \& Reiss, A. L. (2011). A quantitative comparison of NIRS and fMRI across multiple cognitive tasks. NeuroImage, 54(4), 2808- 2821. http://doi.org/10.1016/j.neuroimage.2010.10.069

Davidson, R. J., Kabat-Zinn, J., Schumacher, J., Rosenkranz, M., Muller, D., Santorelli, S. F., ... Sheridan, J. F. (2003). Alterations in brain and immune function produced by mindfulness meditation. Psychosomatic Medicine, 65(4), 564-570. http://doi.org/10.1097/01.psy.0000077505.67574.e3

Davidson, R., \& Lutz, A. (2008). Buddha's Brain: Neuroplasticity and Meditation [In the Spotlight]. IEEE Signal Processing Magazine, 25(1), 176-174. http://doi.org/10.1109/MSP.2008.4431873

Delorme, A., \& Makeig, S. (2004). EEGLAB: An open source toolbox for analysis of single- trial EEG dynamics including independent component analysis. Journal of Neuroscience Methods, 134(1), 9-21. http://doi.org/10.1016/j.jneumeth.2003.10.009

Dietterich, T. G. (2000). Ensemble Methods in Machine Learning. In MCS '00: Proceedings of the First International Workshop on Multiple Classifier Systems (pp. 1-15). http://doi.org/10.1007/3-540-45014-9_1 
Dhyan, P. (2003). theory and practice-Acharya Mahapragya. Jain Vishva Bharati, Ladnun (Raj.), edition.

Elliot, A. J., Maier, M. A., Moller, A. C., Friedman, R., \& Meinhardt, J. (2007). Color and psychological functioning: the effect of red on performance attainment. $J$ Exp Psychol Gen, 136(1), 154-168. http://doi.org/10.1037/0096-3445.136.1.154

Fell, J., Axmacher, N., \& Haupt, S. (2010). From alpha to gamma: Electrophysiological correlates of meditation-related states of consciousness. Medical Hypotheses, 75(2), 218224. http://doi.org/10.1016/j.mehy.2010.02.025

Fernandes, J. A., Irigoien, X., Goikoetxea, N., Lozano, J. A., Inza, I., Pérez, A., \& Bode, A. (2010). Fish recruitment prediction, using robust supervised classification methods. Ecological Modelling, 221(2), 338-352. http://doi.org/10.1016/j.ecolmodel.2009.09.020

Freund, Y., \& Schapire, R. R. E. (1996). Experiments with a New Boosting Algorithm. International Conference on Machine Learning, 148-156. http://doi.org/10.1.1.133.1040

Fukunaga, K. (1990). Statistical Pattern Stas-tical Pattern Recognit ion. Pattern Recognition, 22(7), 833-834. http://doi.org/10.1016/0098-3004(96)00017-9

Galar, M., Fernández, A., Barrenechea, E., Bustince, H., \& Herrera, F. (2011). An overview of ensemble methods for binary classifiers in multi-class problems: Experimental study on one-vs-one and one-vs-all schemes. Pattern Recognition, 44(8), 1761-1776. http://doi.org/10.1016/j.patcog.2011.01.017

Gevins, A., Smith, M. E., McEvoy, L., \& Yu, D. (1997). High-resolution EEG mapping of cortical activation related to working memory: Effects of task difficulty, type of processing, and practice. Cerebral Cortex, 7(4), 374-385. http://doi.org/10.1093/cercor/7.4.374

Guler, I., \& Ubeyli, E. D. (2007). Multiclass Support Vector Machines for EEG-Signals Classification. Information Technology in Biomedicine, IEEE Transactions on, 11(2), 117-126. http://doi.org/10.1109/TITB.2006.879600

Gunaratana, V. H. (2002). Mindfulness in Plain English. East, (April), 224. http://doi.org/10.1037/e613852007-001

Hosseinifard, B., Moradi, M. H., \& Rostami, R. (2011). Classifying depression patients and normal subjects using machine learning techniques. Electrical Engineering (ICEE), 2011 19th Iranian Conference on, 1-4.

Jaskowiak, P. a, \& Campello, R. J. G. B. (2011). Comparing Correlation Coefficients as Dissimilarity Measures for Cancer Classification in Gene Expression Data. 
Kaur, C., \& Singh, P. (2015). EEG Derived Neuronal Dynamics during Meditation: Progress and Challenges. Advances in Preventive Medicine, 2015(2), 1-10.

http://doi.org/10.1155/2015/614723

Khalil, M. M., Tremoleda, J. L., Bayomy, T. B., \& Gsell, W. (2011). Molecular SPECT Imaging: An Overview. International Journal of Molecular Imaging, 2011, 796025. http://doi.org/10.1155/2011/796025

Lazar, S. W., Kerr, C. E., Wasserman, R. H., Gray, J. R., Greve, D. N., Treadway, M. T., ... Fischl, B. (2005). Meditation experience is associated with increased cortical thickness. $\quad$ Neuroreport, 16(17), 1893-7. http://doi.org/10.1097/01.wnr.0000186598.66243.19

Lehmann, D., Faber, P. L., Achermann, P., Jeanmonod, D., Gianotti, L. R. R., \& Pizzagalli, D. (2001). Brain sources of EEG gamma frequency during volitionally meditationinduced, altered states of consciousness, and experience of the self. Psychiatry Research - Neuroimaging, 108(2), 111-121. http://doi.org/10.1016/S0925-4927(01)00116-0

Lotte, F., Congedo, M., Lécuyer, A., Lamarche, F., \& Arnaldi, B. (2007). A review of classification algorithms for EEG-based brain-computer interfaces. Journal of Neural Engineering, 4(2), R1-R13. http://doi.org/10.1088/1741-2560/4/2/R01

Lutz, A., Greischar, L. L., Rawlings, N. B., Ricard, M., \& Davidson, R. J. (2004). Longterm meditators self-induce high-amplitude gamma synchrony during mental practice. Proceedings of the National Academy of Sciences of the United States of America, 101(46), 16369-16373. http://doi.org/10.1073/pnas.0407401101

Lutz, A., Slagter, H. A., Rawlings, N. B., Francis, A. D., Greischar, L. L., \& Davidson, R. J. (2009). Mental training enhances attentional stability: neural and behavioral evidence. The Journal of Neuroscience: The Official Journal of the Society for Neuroscience, 29(42), 13418-27. http://doi.org/10.1523/JNEUROSCI.1614-09.2009

MacLean, K. A., Ferrer, E., Aichele, S. R., Bridwell, D. A., Zanesco, A. P., Jacobs, T. L., ... Saron, C. D. (2010). Intensive meditation training improves perceptual discrimination and sustained attention. Psychological Science: A Journal of the American Psychological Society / APS, 21, 829-839. http://doi.org/10.1177/0956797610371339

Malmivuo, J. A., \& Suihko, V. E. (2004). Effect of skull resistivity on the spatial resolutions of EEG and MEG. IEEE Transactions on Biomedical Engineering, 51(7), 1276-1280. http://doi.org/10.1109/TBME.2004.827255

Matochik, J. A., Zametkin, A. J., Cohen, R. M., Hauser, P., \& Weintraub, B. D. (1996). Abnormalities in sustained attention and anterior cingulate metabolism in subjects with 
resistance to thyroid hormone. Brain Research, 723(1-2), 23-28.

http://doi.org/10.1016/0006-8993(96)00177-1

Michael Murphy, Steven Donovan, E. T. (1997). The physical and psychological effects of meditation: A Review of Contemporary Research. The Physical and Psychological Effects of Meditation: A Review of Contemporary Research with a Comprehensive Bibliography, 1931-1996, 1-23.

Mitra, P., \& Bokil, H. (2009). Observed Brain Dynamics. Observed Brain Dynamics. http://doi.org/10.1093/acprof:oso/9780195178081.001.0001

Mrazek, M. D., Franklin, M. S., Phillips, D. T., Baird, B., \& Schooler, J. W. (2013).

Mindfulness Training Improves Working Memory Capacity and GRE Performance While Reducing Mind Wandering. Psychological Science, 24(5), 776-781. http://doi.org/10.1177/0956797612459659

Muehllehner, G., \& Karp, J. S. (2006). Positron emission tomography. Physics in Medicine and Biology, 51(13), R117--37. http://doi.org/10.1088/0031-9155/51/13/R08

Newberg, A. B., \& Iversen, J. (2003). The neural basis of the complex mental task of meditation: Neurotransmitter and neurochemical considerations. Medical Hypotheses. http://doi.org/10.1016/S0306-9877(03)00175-0

Okogbaa, O. G., Shell, R. L., \& Filipusic, D. (1994). On the investigation of the neurophysiological correlates of knowledge worker mental fatigue using the EEG signal. Applied Ergonomics, 25(6), 355-365. http://doi.org/10.1016/0003-6870(94)90054-X

Pan, W., Zhang, L., \& Xia, Y. (1994). The difference in EEG theta waves between concentrative and non-concentrative qigong states--a power spectrum and topographic mapping study. Journal of Traditional Chinese Medicine = Chung I Tsa Chih Ying Wen Pan / Sponsored by All-China Association of Traditional Chinese Medicine, Academy of Traditional Chinese Medicine, 14(3), 212-218. Retrieved from http://www.ncbi.nlm.nih.gov/pubmed/7799657

Perich, T., Manicavasagar, V., Mitchell, P. B., \& Ball, J. R. (2013). The association between meditation practice and treatment outcome in Mindfulness-based Cognitive Therapy for bipolar disorder. Behaviour Research and Therapy, 51(7), 338-343. http://doi.org/10.1016/j.brat.2013.03.006

Pizzagalli, D. a. (2007). Electroencephalography and High-Density Electrophysiological Source Localization. Handbook of Psychophysiology, 56-84. http://doi.org/10.1017/CBO9780511546396.003 
Qin, Z., Jin, Y., Lin, S., \& Hermanowicz, N. S. (2009). A forty-five year follow-up EEG study of Qigong practice. The International Journal of Neuroscience, 119(4), 538-552. http://doi.org/10.1080/00207450802325520

Sedlmeier, P., Eberth, J., Schwarz, M., Zimmermann, D., Haarig, F., Jaeger, S., \& Kunze, S. (2012). The psychological effects of meditation: A meta-analysis. Psychological Bulletin, 138(6), 1139-1171. http://doi.org/10.1037/a0028168

Sekimoto, M., Kato, M., Watanabe, T., Nakajima, T., Hori, T., Kajimura, N., \& Takahashi, K. (2005). Asymmetric interhemispheric sigma waves during all-night sleep in humans. Sleep and Biological Rhythms, 3(3), 130-135. http://doi.org/10.1111/j.14798425.2005.00174.x

Singer, W., \& Gray, C. (1995). Visual feature integration and the temporal correlation hypothesis. Annual Review of Neuroscience, 18, 555-586. http://doi.org/10.1146/annurev.ne.18.030195.003011

Stinson, B., \& Arthur, D. (2013). A novel EEG for alpha brain state training, neurobiofeedback and behavior change. Complementary Therapies in Clinical Practice, 19(3), 114-118. http://doi.org/10.1016/j.ctcp.2013.03.003

Stone, N. J., \& English, A. J. (1998). Task Type, Posters, and Workspace Color on Mood, Satisfaction and Performance. Journal of Environmental Psychology, 18, 175185. http://doi.org/10.1006/jevp.1998.0084

Suykens, J. A. K., Vandewalle, J., \& De Moor, B. (2001). Optimal control by least squares support vector machines. Neural Networks, 14(1), 23-35. http://doi.org/10.1016/S08936080(00)00077-0

Takahashi, T., Murata, T., Hamada, T., Omori, M., Kosaka, H., Kikuchi, M., ... Wada, Y. (2005). Changes in EEG and autonomic nervous activity during meditation and their association with personality traits. International Journal of Psychophysiology, 55(2), 199207. http://doi.org/10.1016/j.ijpsycho.2004.07.004

Tallon-Baudry, C., Kreiter, a, \& Bertrand, O. (1999). Sustained and transient oscillatory responses in the gamma and beta bands in a visual short-term memory task in humans. Visual Neuroscience, 16(3), 449-459. http://doi.org/10.1017/S0952523899163065

Travis, F. (2001). Autonomic and EEG patterns distinguish transcending from other experiences during Transcendental Meditation practice. International Journal of Psychophysiology, 42(1), 1-9. http://doi.org/10.1016/S01678760(01)00143-X

Travis, F., Haaga, D. A. F., Hagelin, J., Tanner, M., Arenander, A., Nidich, S., ... Schneider, 
R.H. (2010). A self-referential default brain state: Patterns of coherence, power, and eLORETA sources during eyes-closed rest and transcendental meditation practice.

Cognitive Processing, 11(1), 21-30. http://doi.org/10.1007/s10339-009-0343-2

Valverde-Albacete, F. J., \& Peláez-Moreno, C. (2014). 100\% classification accuracy considered harmful: The normalized information transfer factor explains the accuracy paradox. PLoS ONE, 9(1). http://doi.org/10.1371/journal.pone.0084217

Vapnik, V. N. (1995). The Nature of Statistical Learning Theory. Springer (Vol. 8). http://doi.org/10.1109/TNN.1997.641482

Vertes, R. P. (2005). Hippocampal theta rhythm: A tag for short-term memory. Hippocampus. http://doi.org/10.1002/hipo.20118

Walter, C., Cierniak, G., \& Gerjets, P. (2011). Classifying mental states with machine learning algorithms using alpha activity decline. ESANN 2011 Proceedings, European Symposium on Artificial Neural Networks, Computational Intelligence and Machine Learning, (April), 27-29. Retrieved from http://material.bccn.uni-freiburg.de/publicationsbccn/2011/Walter11_405.pdf

Watson, D., Clark, L. a, \& Tellegen, A. (1988). Development and validation of brief measures of positive and negative affect: the PANAS scales. Journal of Personality and Social Psychology, 54(6), 1063-70. http://doi.org/10.1037/0022-3514.54.6.1063

Welch, P. D. (1967). The Use of Fast Fourier Transform for the Estimation of Power Spectra: A Method Based on Time Averaging Over Short, Modified Periodograms. IEEE Transactions on Audio and Electroacoustics, 15(2), 70-73. http://doi.org/10.1109/TAU.1967.1161901

Wilke, M., Holland, S. K., Myseros, J. S., Schmithorst, V. J., \& Ball, W. S. (2003). Functional magnetic resonance imaging in pediatrics. Neuropediatrics, 34(5), 225-33. http://doi.org/10.1055/s-2003-43260

Yoto, A., Katsuura, T., Iwanaga, K., \& Shimomura, Y. (2007). Effects of object color stimuli on human brain activities in perception and attention referred to EEG alpha band response. Journal of Physiological Anthropology, 26(3), 373-379.

Yu, X., Fumoto, M., Nakatani, Y., Sekiyama, T., Kikuchi, H., Seki, Y., Arita, H. (2011). Activation of the anterior prefrontal cortex and serotonergic system is associated with improvements in mood and EEG changes induced by Zen meditation practice in novices. International Journal of Psychophysiology, 80(2), 103-111. 


\section{APPENDIX-1}

\section{Description of Audio File:}

Here is the complete description of audio file that was being played during meditation.

"Welcome to this EEG session. In this session we will have 3 steps (1) one minute of silence sitting with your eyes gently closed (2) Guided Preksha meditation session (3) Again, one minute of silence sitting.

Let's start our journey with a minute of silence with eyes gently closed. Select a comfortable posture, back and neck in a straight line, eyes closed and silence. Now we take on guided Preksha meditation. Select a comfortable posture, back and neck in a straight line, eyes gently close, bring attention to breath, to a present moment. Concentrate your mind on the right legged toe. Suggest the toe to relax, relax the toe, sole, heal, ankle, calf muscles, relax...relax...relax, relax the knee, thigh muscles, relax ...relax.... relax. Experience your right leg is relaxed, relax....relax. Concentrate your mind on the left leg, toes, sole, heal, ankle, calf muscles, knee, thigh muscles upto the hip joint, relax...relax...relax, relax the knee, thigh muscles, relax ...relax....relax. Experience your right leg is relaxed, relax.....relax. Penetrate your mind through the navel, abdominal muscles, relax....relax....relax. Small intestine, large intestine, kidneys, liver, pancreas, stomach, every organ, every muscle, every cell, relax....relax...relax...relax....relax. Experience it relax, relax....relax...relax. Concentrate your mind on the lungs and the heart, relax, relax.....relax...relax...relax. Back muscle, lower 
back, middle back and upper back, relax, relax, relax...relax....relax....relax. Experience the whole back as relaxed...relaxed...relaxed. Bring your attention to the right hand, thumb, fingers, palm, wrist, lower arm, elbow, upper arm relax....relax...relax....relax, left hand from thumb to the shoulders, relax....relax...relax. Concentrate your mind on your throat muscles, relax...relax...relax...relax.....relax. Food pipe, wind pipe, vocal cord relax...relax...relax. Facial muscles, chin, lips, tongue, pallet, relax...relax...relax. Read your mind through the brain, every neuron of the brain relax......relax...relax...relax...relax. Take a moment to come out of the body. Observe the body as an object. Observe your toes, observe your fingers. Observe the skin, penetrate inside. Observe the flush in and out. Observe the body as an object. Experience the difference in the new observed object. Experience the dissociation/disconnection from the body. At this state of pain, we take on a new journey, the journey of the humming sound. A simple exercise where you breathe in long, exhaling, generate this humming sound with your lips closed. As you humm, concentrate your mind in the center of the brain. The humming sound helps to release all your negative thoughts, negative energy, negative emotions. Take a long breath, join me for a while and then you can continue on your own. Inhale long, lips closed, long breath in, exhaling humm. Humm, humm.....humm....humm. Keep going, inhale long and humm. Repeat this, repeat at your own pace. Remember as you exhale humming releases all negative energy. Concentrate your mind at center of the brain, long breath in. Give a pause. Now as we humm, try to breathe in humming, generate the sound, let the sound travel from the navel into the brain, from the brain into the space, travel into the space with your humming sound as far as you can reach. As you travel, experience the freedom, experience a release. Take long breath in. Start your journey again at your own pace as far as you can go. Take a pause, experience the silence, observe the brain. Now we take on the journey of the brain, 
experience yourself to be seated in a beautiful green environment, dense green energy on you, the green trees, green leaves, green flowers, green fruits, green butterflies. The breeze is green. Everything around you is dense green. Feel the presence of green, the freshness, the fragrance, the touch of green. Breathe in the green. Again, breathe in the green. Exhale...As you breathe in experience abundance green energy from the cosmos flowing through you. As you exhale let the toxic contents be released, physical, mental emotion, any instincts release everything out through this green. Breathe in, breathe out.....breathe in, breathe out....breathe out.....breathe in, breathe out........breathe in, breathe out.......breathe in, breathe out. Take on change of every moment, bring attention to your heart chakra. Heart chakra is located near your heart, in your lungs observe the beautiful green light. Try to have mental peace, gaze at this light without blinking your gaze, undistracted mind fully engrossed into this light. Experience the light of glowing and glowing, expanding, let it grow, grow, grow, and expand. The green is the color of healing, green is the color of joy, bliss. Green is the color of compassion. Expand your compassionate breathing. Feel the green filled in your own body. The whole body is filled with blissful energy. Go beyond the body. Expand your blissful presence in the whole room. Seek your blissful presence in the whole room. Go beyond the room into the whole building. Expand as far as you can, from beyond the building into the cosmos. Reach as far as you can into the space with your blissful presence. Experience, you are connected with the whole universe, this green energy of bliss, the only bond you carry. The only relationship we have with this universe is the relationship of bliss and joy, compassion. Feel the compassionate presence connected with the whole universe. Forget your breathe, forget your body, forget the color. The only experience you have is the experience of bliss and joy and compassion, the loving being you are in the universe. Last few moments, forget everything, just experience your blissful experience in the universe.... 
breathe in.... breathe out...breathe in.....breathe out. Long breathe in, come back to this place, to this room, to this body, to this breath. Complete the session with a smile. Now the third step, sit in silence, eyes closed for a minute........session completed. Thank you". 